\title{
Prediction of wind environment and thermal comfort at pedestrian level in urban area
}

\author{
Akashi Mochida $^{\text {a }}$, Yu Fat Lun ${ }^{\mathrm{b}}$ \\ ${ }^{a}$ Tohoku University, \#1202 6-6-11 Aoba, Aramaki Aza, Aoba-ku, Sendai, Japan \\ ${ }^{b}$ Toyohashi University of Technology, 1-1 Hibariga-oka, Tempakucho, Toyohashi, Japan
}

\begin{abstract}
This paper reviews the recent developments of CWE researches for predicting the pedestrian level wind and thermal environments in urban areas. The progress of turbulence models in the last decade and their applications to the problems related to wind climate are firstly and briefly reviewed, and the results of AIJ (Architectural Institute of Japan) collaborative project of cross comparisons of CFD results of wind environments are shown. Next, recent achievements in the field of modeling canopy flows for reproducing the aerodynamic and thermal effects of trees, buildings and automobiles are outlined. Examples of numerical results with tree and vehicle canopy models are shown to demonstrate the significant effects of stationary and non-stationary subgrid scale flow obstacles on turbulent flowfield within street canyons.
\end{abstract}

KEYWORDS: pedestrian level wind environment, thermal comfort, Urban Heat Islands, subgrid scale flow obstacles, tree canopy, vehicle canopy

\section{INTRODUCTION}

The world's urban population was 2.9 billion (47.2\%) in 2000 and is expected to rise to 5 billion (60.2\%) by 2030. During 2000-2030, the world's urban population is projected to grow at an average annual rate of $1.9 \%$ [1]. In line with the rapid urbanisation and growing of urban population, there are increasing concerns on the quality of urban environment. In this respect, urban thermal environment is one of the major concerns, which had lead to numerous researches on this topic.

The urban thermal environment has been worsened by the Urban Heat Island (UHI) effects. The UHI is now regarded as one of the most serious urban environmental problems in the world. The contributing factors of UHI include less vegetation in city area, absorption of solar energy input by concrete and paved surfaces, multiple heat reflections from canyon structures of high-rise buildings, anthropogenic heat releases from air-conditioning systems, automobiles, etc. In order to reduce the UHI effects, various mitigating measures have been proposed. The most commonly applied measures include tree planting. The monetary benefits of urban trees are difficult to quantify because these trees can provide numerous private and public benefits. The latter includes improving thermal environment, reducing community noise and air pollution problems, enhancing biodiversity and meliorating aesthetics [2,3,4]. However, from engineering point of view, the existence of tree covered ground surface is one of the most essential factors to be considered in urban design. Accurate reproduction of aerodynamic effects of trees is also very significant for predicting wind environment in urban area.

Wind environment is one of the most important factors to be considered in UHI study as it has significant influence on UHI effect and outdoor thermal comfort. The conventional urban wind environment assessment methods only took into consideration the influence of topographic features and geometry of buildings (cf. Figure 1(1)). These methods may be inadequate to reflect 
the real conditions of city where there are objects of various scales within the street canyons. Stationary objects (cf. Figure 1(2)) such as trees and telephone boxes, and non-stationary objects (cf. Figure 1(3)) such as moving vehicles and swinging hanging-signboards (commonly seen in Asian countries), may alter the surface roughness to certain extent, and consequently flow separation may be misplaced. In order to obtain accurate quantitative data for urban wind environment assessment, these objects must not be overlooked. In recent years, canopy models for reproducing the aerodynamic and thermal effects of trees, buildings and automobiles have been developed and applied to various problems related to urban climate. The canopy models were incorporated into the meteorological mesoscale models. The simulation methods for mesoscale and micro-scale climates were then integrated into the total simulation system using the nested grid technique.

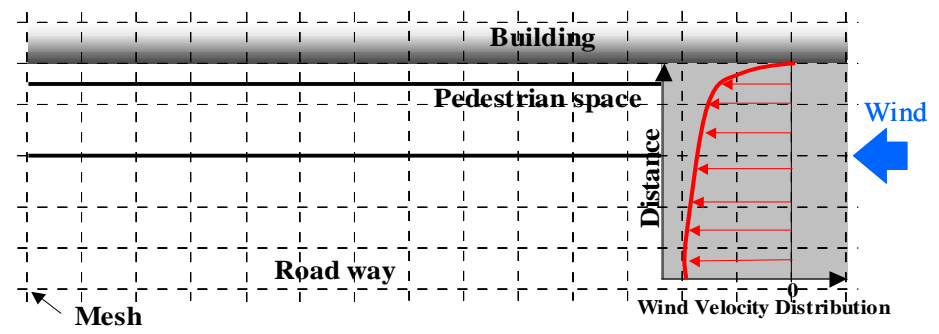

(1) Conventional wind environment assessment considers only the influences of topographic features and geometry of buildings

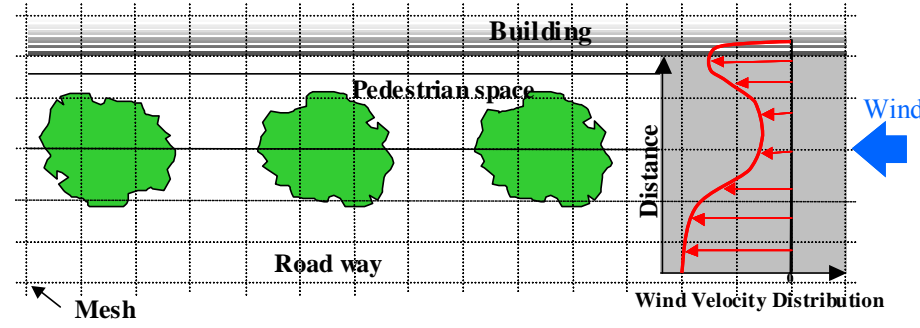

(2) Contemporary trend in wind environment assessment including stationary objects such as trees

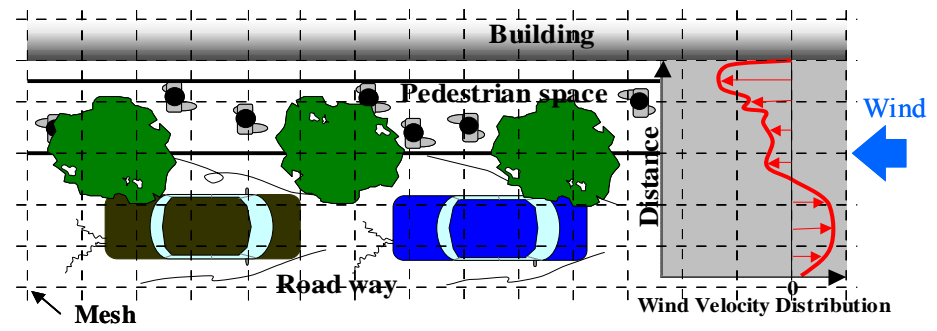

(3) New direction in wind environment assessment integrating nonstationary objects such as automobiles and pedestrians for analyzing urban system integrity

Figure 1. Concept of wind environment assessment: from conventional approach to contemporary tactics.

The growth of CWE applications in the past decade had greatly expanded the scope of wind engineering. Now the application of CWE ranges from the microclimate around a human body to the mesoscale climate in urban area. The aims of this paper are to present the progress of CWE researches for predicting pedestrian level wind environment around buildings together with a brief review on turbulence modeling for CWE applications to problems related to wind environment and cross comparison of predicted results with various turbulence models for several test cases, and to demonstrate the significant effects of stationary and non-stationary objects (tree canopy model and vehicle canopy model respectively) on turbulent diffusion process within street canyons. 


\section{PROGRESS IN TURBULENCE MODELING FOR CWE APPLICATIONS OVER THE PAST 10 YEARS}

\subsection{Appearance of dynamic SGS models and their applications on wind engineering}

The standard Smagorinsky model was widely used in the computation of LES in the CWE researches conducted in the early period. In the Smagorinsky model approach, a simple eddyviscosity type approximation is used to simulate the subgrid scale (SGS) stress $\tau_{\mathrm{ij}}$ in subgridscale. The SGS eddy viscosity, $v_{\mathrm{SGS}}$, is estimated by

$$
v_{\mathrm{SGS}}=\left(\mathrm{C}_{\mathrm{S}} f_{\mu} \bar{\Delta}\right)^{2} \cdot \sqrt{\frac{1}{2}\left(\frac{\partial \bar{u}_{i}}{\partial x_{j}}+\frac{\partial \bar{u}_{j}}{\partial x_{i}}\right)^{2}}=\mathrm{C}\left(f_{\mu} \bar{\Delta}\right)^{2} \cdot \sqrt{\frac{1}{2}\left(\frac{\partial \bar{u}_{i}}{\partial x_{j}}+\frac{\partial \bar{u}_{j}}{\partial x_{i}}\right)^{2}}=\mathrm{C}\left(f_{\mu} \bar{\Delta}\right)^{2}|\overline{\mathrm{S}}|
$$

where, $\bar{f}$ : filtered quantities,

$\bar{\Delta}$ : the grid-filter width,

$f_{\mu}$ : the wall damping function.

In the standard Smagorinsky model, one value of the Smagorinsky constant, Cs, must be selected. The Smagorinsky constant Cs was optimized from 0.1 to 0.25 for various flowfields. Since the flowfield around a bluff body involves various types of flow properties such as impinging, separation, free shear layer, vortex shedding etc., it is arduous to determine an appropriate value of Cs for analyzing the whole flowfield around the bluff body. The dynamic SGS model, which was proposed by Germano et al. in 1991 [5] and revised by Lilly in 1992 [6], successfully corrected this fault of the standard Smagorinsky model. In the Dynamic SGS model, based on the Smagorinsky model (hereafter denoted by DS model), the value of model coefficient $\mathrm{C}$ $\left(=\mathrm{Cs}^{2}\right)$ was determined as a variable of space and time following the properties of the flowfield, using two filters with different characteristic scales i.e. grid filter and test filter [5]. The details of this model are available in many papers [6-13].

It was affirmed in 1990s that the prediction accuracy of the static type Smagorinsky model could be improved by the DS model [8-11]. However, computation based on the DS model was not stable as the fluctuation of $\mathrm{C}$ was too large. In order to stabilize the fluctuation of $\mathrm{C}$, various techniques and models had later been proposed [12-22]. When the flowfield has a homogeneous direction (e.g. channel flow), $\mathrm{C}$ can be calculated using the averaged quantity of the homogeneous direction. However, this technique cannot be used in many problems in wind engineering which deals with three-dimensional (3D) flow around a bluff body. To deal with such 3D flow, the Lagrangian Dynamic model proposed by Menevenu et al. [14] is useful. In this model, C is calculated using the averaged quantities along the flow path line instead of using quantities averaged over the homogeneous direction. By the advice of Prof. Squires, the present authors applied this model to flow past a square cylinder and found that this model remarkably improved on both calculation stability and prediction accuracy when a proper length scale was imposed on Lagrangian averaging $[15,16]$.

It is widely known that the DS model requires the principal axes of the SGS stress term $\tau_{\mathrm{ij}}$ be aligned with the strain-rate tensor and this brings about an excessive energy back-scattering when $\mathrm{C}$ becomes negative. In order to overcome this shortcoming, the Dynamic Mixed model (hereafter denoted by DM model) was proposed by Zang et al. [17] and revised by Vreman et al. [18] as a linear combination of the DS model and the scale-similarity model [19] to control the extent of excessive back-scattering. The basic equations of DM model are shown in the following equations: 


$$
\begin{aligned}
& \tau_{\mathrm{ij}}-\frac{1}{3} \delta_{\mathrm{ij}} \tau_{\mathrm{kk}}=\frac{-2 v_{\mathrm{SGS}} \overline{\mathrm{S}}_{\mathrm{ij}}}{\mathrm{S}_{\begin{array}{c}
\text { Smagorinsky } \\
\text { model }
\end{array}}} \frac{\mathrm{B}_{\mathrm{ij}}-\frac{1}{3} \delta_{\mathrm{ij}} \mathrm{B}_{\mathrm{kk}}}{\overline{\begin{array}{c}
\text { scale-similarity } \\
\text { model }
\end{array}}} \\
& =-2 C \bar{\Delta}^{2}|\bar{S}| S_{i j}+B_{i j}-\frac{1}{3} \delta_{i j} B_{k k} \\
& B_{i j}=\overline{\bar{u}}_{i} \overline{\mathrm{u}}_{\mathrm{j}}-\overline{\overline{\mathrm{u}}}_{\mathrm{i}} \overline{\overline{\mathrm{u}}}_{\mathrm{j}}
\end{aligned}
$$

where, $\mathrm{C}$ in eq. (2) is given by utilizing the dynamic procedure [6]. Tominaga et al. [20-22] applied the DM model to simulate the flow past a bluff body and gas diffusion around a building. It was confirmed that this model yielded better results compared to the DS model.

Recently, Iizuka and Kondo studied the flow over a two-dimensional hill using the DS model [23]. In their results, the DS model showed very poor agreement with the experiment results. It was mainly due to the poor prediction accuracy in region near the ground surface. In order to overcome this drawback, they proposed a hybrid SGS model, i.e. a combination of static and dynamic types of the Smagorinsky model. Iizuka et al. [24] also pointed out that the DM model significantly under-predicts the mean velocity values in the central region of channel flow. Inagaki et al. [25] developed a new static type of the SGS model based on the "mixed timescale" concept proposed by Nagano et al. [26]. The performance of this model was examined for flow over a two-dimensional hill by Iizuka and Kondo [27].

\subsection{Generation of inflow turbulence for LES}

For the application of LES on a flowfield with obstacles, the technique for providing the inflow boundary condition is particularly important since the inflow condition adopted is always turbulent in wind engineering. In order to generate turbulent velocity fluctuations at the inflow boundary, several techniques have been developed [28-37]. The simplest method is to store the time history of velocity fluctuations given from a preliminary LES computation [28]. Another approach is the artificial generation method in which velocity fluctuations are given by inversing the Fourier transform of prescribed energy spectrum with target turbulence intensity and length scale [29]. Methods of generating the inflow turbulence for CWE applications based on this approach were developed by Kondo et al. [30-32], Iizuka et al. [33,34] and Maruyama et al. [35]. The third method is to set the driver section at the upstream region of the main computational domain to generate the inflow turbulence. Lund proposed the method for generating 3D timedependent turbulent inflow data for LES of spatially developing boundary layers [36]. Kataoka et al. [37] simplified Lund's method by assuming the boundary layer thickness is constant within the driver section. This method is now widely used in LES applications on wind engineering problems [38-40].

\subsection{Applications of second-moment closure models on wind engineering problems}

ASM (Algebraic Stress Model) [41,42] and DSM (or RSM, Differential Second-moment Closure Model or Reynolds Stress Equation Mendel) [43] were applied to bluff bodies [44-47]. A number of DSM models were proposed during early 1990s. The major topic was the revision of modeling for pressure-strain correlation term, including the higher-order models proposed by Fu-Launder-Tselepidakis (FLT model) [48] and Speziale-Sarkar-Gatski (SSG model) [49]. Concerning the wall reflection term, the present authors pointed out the shortcoming of the Gibson- 
Launder model [50]. The stress normal to the wall should be suppressed in the impinging region while the Gibson-Launder model increases it $[44,46]$. Craft-Launder proposed a revised model in which this drawback was rectified [51].

Ooka et al. applied various DSM models to the flowfield around a cube [45-48]. Their DSM results did not show any overestimation of turbulent energy $\mathrm{k}$ around the frontal corner, which is peculiar to the $\mathrm{k}-\varepsilon$ model $[55,56]$. However, the lengths of separation region were overestimated in all trials of DSM. LES based on the simple standard Smagorinsky model gave much better prediction in comparison with DSM. Similar tendency of the drawbacks of DSM when applied to flow around a cube were also reported in the $6^{\text {th }}$ ERCOFTAC/IAHR/COST workshop on the refined flow modeling (organized by Profs. Hanjalic and Obi, Delft, 1997 [54]). The present authors withdrew to improve the prediction accuracy of DSM applied to flow around a bluff body. Instead, the authors shifted their attention to the revision of k- $\varepsilon$ model as described in the next section.

\subsection{Revisions of $k-\varepsilon$ models and their applications to wind engineering problems}

It is widely known that the standard $k-\varepsilon$ model has a serious drawback in over-estimating turbulence kinetic energy, $\mathrm{k}$, in the flow with impinging [55,56]. Although this problem does not occur in LES computations, the computational resource required for LES is large and is still beyond the scope of practical applications in CWE. Thus, $\mathrm{k}-\varepsilon$ model is still favorable due to its simplicity and cost effectiveness. Several revised k- $\varepsilon$ models have been proposed to overcome the drawback of the standard k- $\varepsilon$ model and their performance have been tested for flow around a building, city block, actual building complex and flow over hilly terrains.

\section{1) LK and MMK models}

Launder and Kato proposed a revised k- $\varepsilon$ model (hereafter denoted by LK model) $[57,58]$ in which the production term $\mathrm{P}_{\mathrm{k}}$ in the transport equation of turbulent energy $\mathrm{k}$ was changed from $P_{k}=v_{t} S^{2}$ to $P_{k}=v_{t} S \Omega$, as shown in Table 2 ( in this paper, $<>$ denotes ensemble-averaged quantities). They applied the LK model to a $2 \mathrm{D}$ oscillating square cylinder and obtained quite good results. With this revision, the over-estimation of $\mathrm{k}$ around the frontal corner was remarkably improved [57,58]. This simple revision was very successful when applied to a single 2D cylinder with wind direction of zero angle of incidence. The increase of computer processing time due to this modification was very small. The LK model is very easily modified from the original standard k- $\varepsilon$ model and its computation stability is also very good in comparison to the nonlinear $\mathrm{k}-\varepsilon$ models [59-61]. Thus, the LK model is often applied to the flowfield around a bluff body [62-64]. However, this model has two faults requiring revision. First, the LK model contributes to a decrease in turbulent energy $\mathrm{k}$ at the area where $\Omega<\mathrm{S}$, as shown in its definitions (cf. eq. (7) in Table 1). However, it overestimates the value of $P_{k}$ in comparison to the standard $k-\varepsilon$ model where $\Omega>$ S. The area $\Omega>S$ often appears around a bluff body. This drawback of the LK model became more serious in the analysis of flowfield where several bluff bodies were arranged, as the area $\Omega>S$ increased in this situation. The second drawback of the LK model is a mathematical inconsistency in the modeling of Reynolds stress $-<\mathrm{u}_{\mathrm{i}}{ }^{\prime} \mathrm{u}_{\mathrm{j}}>$ and $\mathrm{P}_{\mathrm{k}}$. In the transport equation of mean flow energy $\mathrm{K}\left(=<\mathrm{u}_{\mathrm{i}}><\mathrm{u}_{\mathrm{i}}>/ 2\right)$, there is a term which has the same form as that of $\mathrm{P}_{\mathrm{k}}$ with the opposite sign. This term plays a role in transferring the kinetic energy from mean flow to turbulence. In the case of the original LK model, the term corresponding to $P_{k}$ in the equation of mean flow energy $\mathrm{K}$ did not take the same form as $\mathrm{P}_{\mathrm{k}}$ in the equation of turbulent energy $\mathrm{k}$. This is because the LK model only revised the expression of $\mathrm{P}_{\mathrm{k}}$ in the equation of $\mathrm{k}$. Therefore, $\mathrm{P}_{\mathrm{k}}$ in the equation of mean flow energy $\mathrm{K}$ and that in the equation of turbulent energy $\mathrm{k}$ did not appear in the same form. 
Murakami, Mochida, Kondo et al. proposed a new revision of the k- $\varepsilon$ model, i.e. MMK model [65], which corrected these two drawbacks in the LK model by adding the modification not to the expression for $P_{k}$ but to the expression for eddy viscosity, $v_{t}$ (cf. eqs. (10)-(11) in Table 1).

Table 1. Model equations for LK and MMK models [57,58,65]

$$
\begin{aligned}
& \text { 1. Standard k- } \varepsilon \text { model } \\
& \mathrm{P}_{\mathrm{k}}=v_{\mathrm{t}} \mathrm{S}^{2} \quad \text { (4) } \quad\left(v_{\mathrm{t}}: \text { eq.(5)), } \quad v_{\mathrm{t}}=\mathrm{C}_{\mu} \frac{\mathrm{k}^{2}}{\varepsilon} \quad \text { (5), } \mathrm{S}=\sqrt{\frac{1}{2}\left(\frac{\partial<\mathrm{u}_{\mathrm{i}}>}{\partial \mathrm{x}_{\mathrm{j}}}+\frac{\partial<\mathrm{u}_{\mathrm{j}}>}{\partial \mathrm{x}_{\mathrm{i}}}\right)^{2}}\right. \\
& \text { 2. LK model } \\
& P_{k}=v_{t} S^{2} \quad(9) \quad\left(v_{t}\right. \text { : eq.(10) or (11)) } \\
& v_{\mathrm{t}}=\mathrm{C}_{\mu}^{*} \frac{\mathrm{k}^{2}}{\varepsilon}, \mathrm{C}_{\mu}^{*}=\mathrm{C}_{\mu} \frac{\Omega}{\mathrm{S}} \quad\left(\frac{\Omega}{\mathrm{S}}<1\right) \\
& v_{\mathrm{t}}=\mathrm{C}_{\mu}^{*} \frac{\mathrm{k}^{2}}{\varepsilon}, \mathrm{C}_{\mu}^{*}=\mathrm{C}_{\mu} \quad\left(\frac{\Omega}{\mathrm{S}} \geq 1\right)
\end{aligned}
$$

\section{MMK model}$$
\mathrm{P}_{\mathrm{k}}=v_{\mathrm{t}} \mathrm{S} \Omega \quad(7) \quad\left(v_{\mathrm{t}} \text { : eq.(5)), } \Omega=\sqrt{\frac{1}{2}\left(\frac{\partial<\mathrm{u}_{\mathrm{i}}>}{\partial \mathrm{x}_{\mathrm{j}}}-\frac{\partial<\mathrm{u}_{\mathrm{j}}>}{\partial \mathrm{x}_{\mathrm{i}}}\right)^{2}}\right.
$$

2) New k- $\varepsilon$ models adjusting the turbulence time-scale

Recently, new types of revised k- $\varepsilon$ models, in which the turbulence time-scale is adjusted in accordance with the property of predicted flowfield, have been proposed.

In $\mathrm{k}-\varepsilon$ models, the eddy viscosity, $v_{\mathrm{t}}$ was expressed as

$v_{t}=C_{\mu} k \tau$

where, $\tau$ in eq. (12) is the turbulence time-scale. In the standard $\mathrm{k}-\varepsilon$ model, $\tau=\frac{k}{\varepsilon}$

Durbin proposed eq. (14) for $\tau$ based on the "realizability" constraint, $0 \leq\left\langle u_{\alpha}^{\prime} u_{\alpha}^{\prime}\right\rangle \leq 2 k$ via a bound on the time-scale, $\tau$, where summation was not taken in $\left\langle u_{\alpha}^{\prime} u_{\alpha}^{\prime}\right\rangle[66]$.

The proposed bound on the time-scale is,

$\tau=\min \left(\tau_{u}, \tau_{D}\right)$

where,

$\tau_{u}=\frac{k}{\varepsilon}$

$$
\tau_{D}=\frac{1}{C_{\mu} \sqrt{6|S|^{2}}}
$$

$|S|^{2}=S_{i j} S_{i j}$ and $S_{i j}$ is the rate of mean strain tensor given by

$$
S_{i j}=\frac{1}{2}\left(\frac{\partial\left\langle u_{i}\right\rangle}{\partial x_{j}}+\frac{\partial\left\langle u_{j}\right\rangle}{\partial x_{i}}\right)
$$

The present authors applied this model to flow past a bluff body and confirmed that its result showed good agreement with experimental data in comparison with other revised k- $\varepsilon$ models [67-69]. Nakayama, Kurabuchi, Ohba et al. also reported the high performance of this model when applied to the flow in and around a building under cross-ventilation [70]. However, Lun et 
al. pointed out that this model severely overestimated the size of reverse flow region behind a two-dimensional hill [71].

Another type of revised model adjusting the turbulence time-scale was proposed by Nagano and Hattori [72]. This model introduced a mixed time-scale $\left(\tau_{\mathrm{m}}\right)$, which is a harmonic balance of the turbulent time-scale $\tau_{\mathrm{u}}: \mathrm{k} / \varepsilon$ and the time-scale of mean velocity gradient. Various expressions for estimating $\tau_{\mathrm{m}}$, namely $\mathrm{S}$ model, $\Omega$ model and $\mathrm{S}-\Omega$ model expressed as eqs. (18-1), $(18-2)$ and (18-3), respectively were proposed and tested [72].

$$
\begin{array}{ll}
\frac{1}{\tau_{m}}=\frac{1}{2}\left(\frac{1}{\tau_{u}}+\frac{C_{s}}{\tau_{s}}\right) & (\mathrm{S} \text { model }) \\
\frac{1}{\tau_{m}}=\frac{1}{2}\left(\frac{1}{\tau_{u}}+\frac{C_{s}}{\tau_{\Omega}}\right) & (\Omega \text { model }) \\
\frac{1}{\tau_{m}}=\frac{1}{2}\left(\frac{1}{\tau_{u}}+\frac{C_{s}}{\tau_{S-\Omega}}\right) & (\mathrm{S}-\Omega \text { model })
\end{array}
$$

where,

$$
\begin{aligned}
& \tau_{s}=\frac{1}{\sqrt{|S|^{2}}} \\
& \tau_{\Omega}=\frac{1}{\sqrt{|\Omega|^{2}}} \\
& \tau_{S-\Omega}=\frac{2}{\sqrt{|S|^{2}}+\sqrt{|\Omega|^{2}}} \\
& |\Omega|^{2}=\Omega_{i j} \Omega_{i j}, \\
& \Omega_{i j}=\frac{1}{2}\left(\frac{\partial\left\langle u_{i}\right\rangle}{\partial x_{j}}-\frac{\partial\left\langle u_{j}\right\rangle}{\partial x_{i}}\right) \\
& \text { and } C_{s}=0.4
\end{aligned}
$$

In these models, $\tau$ in eq. (12) was replaced by $\tau_{\mathrm{m}}$, derived from eqs. (18-1), (18-2) and (18$3)$. The performances of these models for flow over hilly terrain [71,73] and flow around a cube $[74,75]$ have been examined by the present authors. Fig. 2 shows the vertical profiles of mean streamwise velocity at various positions over a two-dimensional hill model, in comparison with experimental results [76]. A revised k- $\varepsilon$ model proposed by Durbin [66] and the S- $\Omega$ model proposed by Nagano and Hattori [72] were employed in this simulation. It was clearly shown that the result of Durbin model deviated from experiment in the region behind the hill. A large recirculation occurred along the downstream of the hill. The large re-circulation zone observed behind the hill, in the case of Durbin model, is rectified by the newly proposed S- $\Omega$ model.

S- $\Omega$ model was incorporated into the Local Area Wind Energy Prediction System (LAWEPS) developed by Murakami, Nagano, Mochida, Kato, Kataoka, Otuka et al. [73]. The project for developing LAWEPS was funded by the New Energy and Industrial Technology Development Organization (NEDO) of Japan. The project commenced in 1999 and completed in 2003 [Note 1]. 


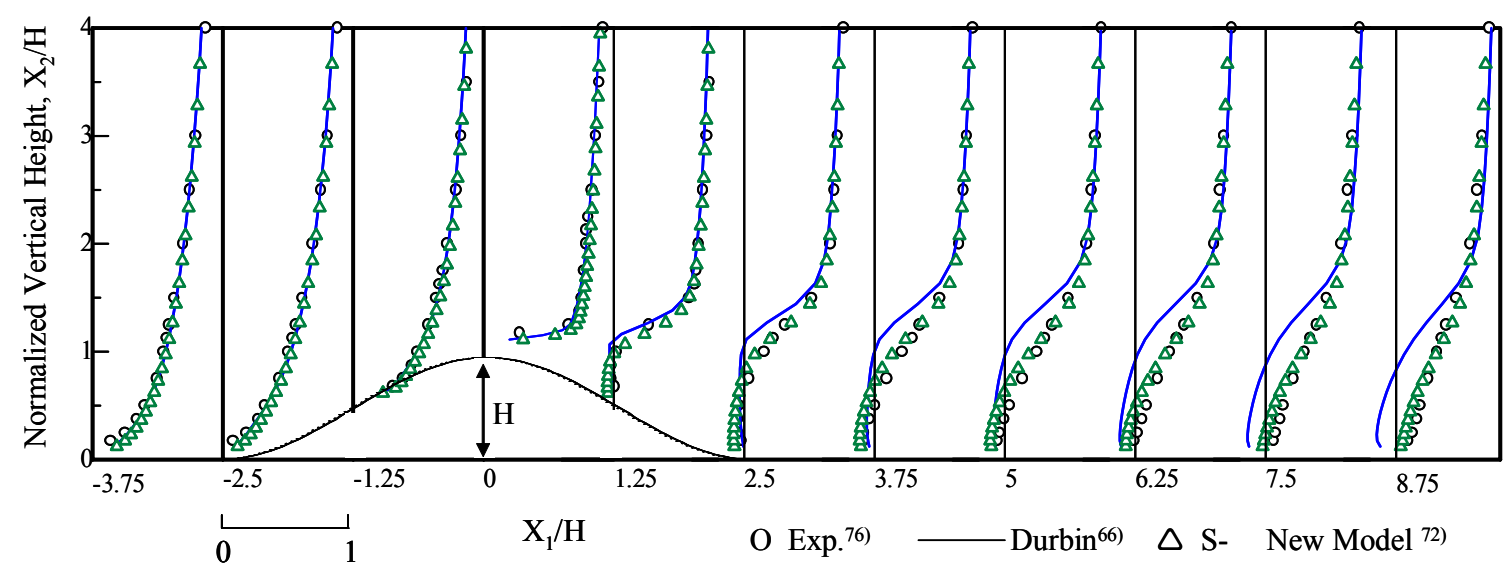

Figure 2. Comparison of mean streamwise velocity around a 2D hill model $[71,73]$

3) Revision of k- $\varepsilon$ model incorporating the buoyancy effects on turbulent diffusion

In recent years, the quality of outdoor thermal environment has been regarded as important as that of indoor thermal environment, and a lot of CFD analyses of outdoor thermal environment have been conducted. Since the temperature difference between urban surfaces is significantly large, the effects of buoyancy on turbulent diffusion should be carefully considered for this type of analysis, and the conventional k- $\varepsilon$ models based on the Eddy-Viscosity Concept is clearly inadequate. The present authors have adopted the WET model proposed by Launder [77] and the revised k- $\varepsilon$ model including buoyancy effects as shown in Table 2 for the analysis of outdoor climate [78]. The revised $\mathrm{k}-\varepsilon$ model in Table 2 was derived from the simplification of WET model.

Table 2. New model for sensible and latent heat fluxes including buoyancy effects [78]

$$
\begin{aligned}
& \text { 1. Sensible heat flux : } \quad-\left\langle u_{3}^{\prime} \theta^{\prime}\right\rangle=\frac{v_{t}}{\sigma_{\theta}} \frac{\partial\langle\theta\rangle}{\partial x_{3}}+\frac{k}{\varepsilon} C_{\theta 3} g_{3} \beta\left\langle\theta^{\prime 2}\right\rangle \\
& \text { 2. Latent heat flux : } \quad-\left\langle u_{3}^{\prime} q_{w}^{\prime}\right\rangle=\frac{v_{t}}{\sigma_{w}} \frac{\partial\left\langle q_{w}\right\rangle}{\partial x_{3}}+\frac{k}{\varepsilon} C_{\theta 3} g_{3} \beta\left\langle\theta^{\prime} q_{w}^{\prime}\right\rangle \\
& q_{w} \text { :mixing ratio of total water } \\
& g_{3}=-9.8 \mathrm{~m} / \mathrm{s}^{2}, \mathrm{C}_{\theta 1}=0.25, \mathrm{C}_{\theta 3}=0.25, \sigma_{\theta}=0.5, \sigma_{w}=0.5
\end{aligned}
$$

\subsection{AIJ collaborative research project \\ - cross comparisons of CFD results of wind environment at pedestrian level -}

Recently, the prediction of wind environment around a high-rise building using CFD technique was being carried out at the practical design stage. However, there were very few studies examined its accuracy, including the velocity distribution at pedestrian level. Hence, a working group for CFD prediction of wind environment around buildings, which consisted of researchers from several universities and private companies [Note 2], was organized in the AIJ(Architectural Institute of Japan). During initial stage of that project, the working group carried out cross comparisons of CFD results of flow around a single high-rise building block placed within the surface boundary layer and flow within a building complex in an actual urban area, obtained from 
various k- $\varepsilon$ models, DSM and LES [67-69,80-84]. Fig.3 illustrates six test cases for these cross comparisons. They were done in order to clarify the major factors which affect the prediction accuracy. In order to assess the performance of turbulence models, the results should be compared under the same computational conditions. Special attentions were paid to this point in this project. The computational conditions, i.e., grid arrangements, boundary conditions, etc., were specified by the organizers. Contributors were requested to follow the conditions. Here results of two cases, Cases A and E, are shown.

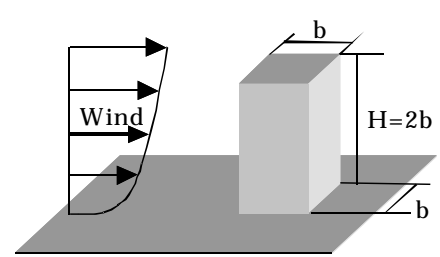

(1) Test Case A (2:1:1 square prism)

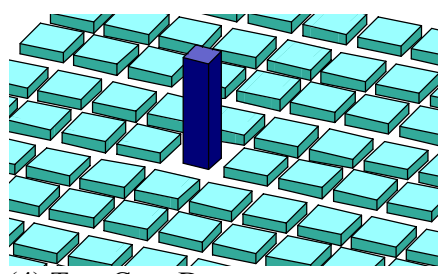

(4) Test Case D

( a high-rise building in city )

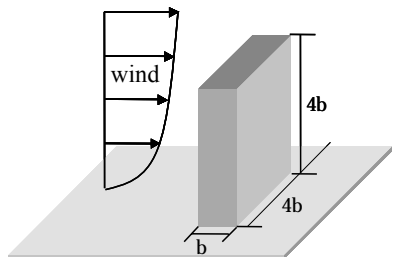

(2) Test Case B (4:4:1 square prism)

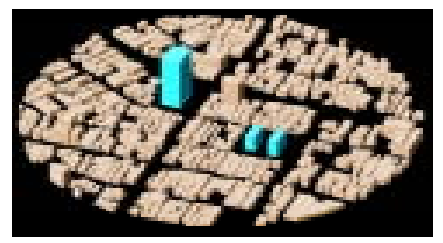

(5) Test Case E ( Building complexes in actual urban areas (Niigata))

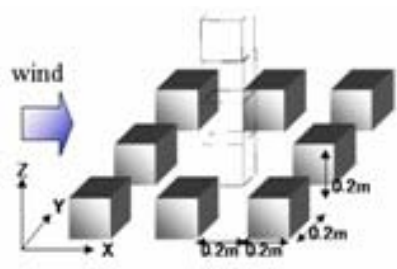

(3) Test Case C (simple city block )

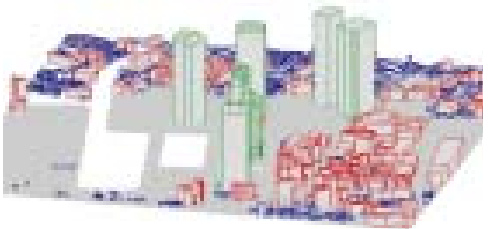

(6) Test Case F ( Building complexes in actual urban areas (Shinjuku))

Figure 3. Six test cases for comparison.

1) Test Case A (2:1:1 shaped building model)

Outlines of the computed cases for 2:1:1 shaped building model (Test Case A) are listed in Table 3. Nine groups have submitted a total of eighteen datasets of results. The performance of the standard k- $\varepsilon$ and five types of revised k- $\varepsilon$ models was examined. Furthermore, Differential Stress Model (DSM) [45], Direct Numerical Simulation (DNS) with third-order upwind scheme [85] and Large Eddy Simulation (LES) using the Smagorinsky subgrid-scale model [87] were also included in the comparison exercise.

The predicted reattachment lengths on the roof, $\mathrm{X}_{\mathrm{R}}$, and that behind the building, $\mathrm{X}_{\mathrm{F}}$, were given for all cases as shown in Table 3 . In the results of the standard k- $\varepsilon$ (KE1 8), the reverse flow on the roof, which was clearly observed in the experiment, was not reproduced. On the other hand, the reverse flow on the roof appeared in the results of all the revised k- $\varepsilon$ models (LK1, RNG1, MMK1, RNG1, LK2, LK3, MMK2, DBN) though its size was a little larger than that of the experiment. In the DSM result, the separated flow from a windward corner was predicted too large, and does not reattach to the roof. The result of LES without inflow turbulence (LES1) can reproduce the reattachment on the roof, but $X_{R}$ is somewhat overestimated in this case. On the other hand, the result of LES with inflow turbulence (LES2) shows close agreement with the experiment.

The reattachment length behind the building, $\mathrm{X}_{\mathrm{F}}$, was evaluated larger than the experiment in all cases by the standard and revised k- $\varepsilon$ models. It is surprising to see that there were significant differences in $\mathrm{X}_{\mathrm{F}}$ values between the results of the standard k- $\varepsilon$ model. As was already noted, the grid arrangements and boundary conditions were set to be identical in all cases, and QUICK scheme was used for convection terms in many cases. The reason for the difference in 
$\mathrm{X}_{\mathrm{F}}$ values predicted by the standard k- $\varepsilon$ models is not clear, but it may be partly due to the difference in some details of numerical conditions, e.g. the convergence condition, etc. The results of the revised k- $\varepsilon$ models except for the Durbin's model were in the tendency to evaluate $\mathrm{X}_{\mathrm{F}}$ larger than the standard k- $\varepsilon$. This discrepancy was improved in LES and DNS computations. On the other hand, DSM greatly over-estimated $\mathrm{X}_{\mathrm{F}}$. The over-estimation of reattachment length behind a three-dimensional obstacle was also reported by Lakehal and Rodi [63].

The size of the recirculation region behind the building is strongly affected by the momentum transfer mechanism in the wake region, where vortex shedding plays an important role. Thus, the reproduction of vortex shedding is significantly important for accurate prediction of $\mathrm{X}_{\mathrm{F}}$ value. However, none of the $\mathrm{k}-\varepsilon$ models compared here could reproduce vortex shedding. This results in underestimation of the mixing effects in the lateral direction causing a large recirculation region behind the building.

Table 3. Computed cases for 2:1:1 shaped building model (Test Case A)

\begin{tabular}{|c|c|c|c|c|c|c|c|}
\hline Affiliation & CASE & Software & Turbulence model & $\begin{array}{l}\text { Scheme for con- } \\
\text { vection terms }\end{array}$ & $\begin{array}{l}\text { Computational } \\
\text { method and time } \\
\text { integral scheme }\end{array}$ & $\mathrm{X}_{\mathrm{R}} * / \mathrm{b}$ & $\mathrm{X}_{\mathrm{F}} * / \mathrm{b}$ \\
\hline A & KE1 & $\begin{array}{l}\text { STREAM } \\
\text { ver. } 2.10\end{array}$ & $\mathrm{k}-\varepsilon($ standard $)$ & QUICK & $\begin{array}{c}\text { SIMPLE,steady } \\
\text { solution }\end{array}$ & - & 2.54 \\
\hline B & KE2 & $\begin{array}{l}\text { STREAM } \\
\text { ver. } 2.10\end{array}$ & $\mathrm{k}-\varepsilon$ (standard) & $\begin{array}{c}\text { QUICK } \\
\text { (1st-order upwind } \\
\text { for } \mathrm{k} \text { and } \varepsilon \text { ) }\end{array}$ & $\begin{array}{l}\text { SIMPLE,steady } \\
\text { solution }\end{array}$ & 一 & 1.66 \\
\hline \multirow{2}{*}{$\mathrm{C}$} & KE3 & \multirow{2}{*}{$\begin{array}{l}\text { STREAM } \\
\text { ver. } 2.10\end{array}$} & $\mathrm{k}-\varepsilon$ (standard) & \multirow{2}{*}{ QUICK } & \multirow{2}{*}{$\begin{array}{l}\text { SIMPLE,steady } \\
\text { solution }\end{array}$} & - & 2.00 \\
\hline & LK1 & & $\mathrm{k}-\varepsilon(\mathrm{LK})^{57)}$ & & & 0.87 & 2.98 \\
\hline \multirow{2}{*}{ D } & KE4 & \multirow{2}{*}{$\begin{array}{l}\text { STREAM } \\
\text { ver. } 2.10\end{array}$} & k- $\varepsilon$ (standard) & QUICK & \multirow{2}{*}{$\begin{array}{l}\text { SIMPLE,steady } \\
\text { solution }\end{array}$} & - & 2.00 \\
\hline & RNG1 & & $\mathrm{k}-\varepsilon(\mathrm{RNG})^{86)}$ & QUICK & & 0.50 & 2.80 \\
\hline E & KE5 & $\begin{array}{l}\text { STAR-LT } \\
\text { ver.2.0 }\end{array}$ & $\mathrm{k}-\varepsilon$ (standard) & QUICK & $\begin{array}{c}\text { SIMPLE,steady } \\
\text { solution }\end{array}$ & - & 2.20 \\
\hline $\mathrm{F}$ & MMK1 & Homemade & $\mathrm{k}-\varepsilon(\mathrm{MMK})^{65)}$ & QUICK & $\begin{array}{l}\text { MAC, unsteady so- } \\
\text { lution with implicit } \\
\text { scheme }\end{array}$ & 0.65 & 2.72 \\
\hline \multirow{10}{*}{ G } & KE6 & \multirow{2}{*}{$\begin{array}{l}\text { FLUENT } \\
\text { ver.5.0 }\end{array}$} & $\mathrm{k}-\varepsilon$ (standard) & \multirow{2}{*}{ Central } & \multirow{2}{*}{$\begin{array}{c}\text { SIMPLE,steady } \\
\text { solution }\end{array}$} & - & 2.41 \\
\hline & RNG2 & & $\mathrm{k}-\varepsilon(\mathrm{RNG})^{86)}$ & & & 0.58 & 3.34 \\
\hline & KE8 & \multirow{8}{*}{ Homemade } & $\mathrm{k}-\varepsilon$ (standard) & \multirow{6}{*}{ QUICK } & \multirow{6}{*}{$\begin{array}{l}\text { HSMAC, unsteady } \\
\text { solution with im- } \\
\text { plicit scheme }\end{array}$} & - & 2.70 \\
\hline & LK2 & & $\mathrm{k}-\varepsilon(\mathrm{LK})^{57)}$ & & & 0.58 & 3.19 \\
\hline & LK3 & & $\mathrm{k}-\varepsilon\left(\right.$ modified LK) ${ }^{88)}$ & & & 0.53 & 3.11 \\
\hline & MMK2 & & $\mathrm{k}-\varepsilon(\mathrm{MMK})^{65)}$ & & & 0.52 & 3.09 \\
\hline & DBN & & k- $\varepsilon$ (Durbin) ${ }^{66)}$ & & & 0.63 & 2.70 \\
\hline & DSM & & $\mathrm{DSM}^{45)}$ & & & $>1.0$ & 4.22 \\
\hline & LES1 & & $\begin{array}{l}\text { LES(without inflow } \\
\text { turbulence) }\end{array}$ & \multirow[t]{2}{*}{$\begin{array}{l}\text { Second-order cen- } \\
\text { tered difference }\end{array}$} & \multirow{2}{*}{$\begin{array}{c}\text { SMAC, } \\
\text { Convection terms: } \\
\text { Adams-Bashforth } \\
\text { scheme } \\
\text { Diffusion terms: } \\
\text { Crank-Nicolson } \\
\text { scheme }\end{array}$} & 0.62 & 1.02 \\
\hline & LES2 & & $\begin{array}{l}\text { LES(with inflow } \\
\text { turbulence) }\end{array}$ & & & 0.50 & 2.10 \\
\hline $\mathrm{H}$ & KE7 & Homemade & $\mathrm{k}-\varepsilon$ (standard) & QUICK & $\begin{array}{l}\text { HSMAC, unsteady } \\
\text { solution with im- } \\
\text { plicit scheme }\end{array}$ & - & 1.98 \\
\hline I & DNS & Homemade & $\mathrm{DNS}^{85)}$ & $\begin{array}{l}\text { 3rd-order Upwind } \\
\text { Scheme }\end{array}$ & $\begin{array}{c}\text { Artificial com- } \\
\text { pressibility } \\
\text { method, explicit }\end{array}$ & 0.92 & 2.05 \\
\hline \multicolumn{6}{|c|}{ Experiment [89] } & 0.52 & 1.42 \\
\hline
\end{tabular}

${ }^{*} \mathrm{X}_{\mathrm{R}}$ : Reattachment length on the roof

$*^{*} \mathrm{X}_{\mathrm{F}}$ : Reattachment length behind the building 
2) Test Case E ( building complex in actual urban area )

Prediction accuracy for wind environment within an actual building complex, located in Niigata City, Niigata Prefecture, Japan, was examined in this test case. The prediction was carried out by three different codes for comparison, namely a homemade CFD code and two commercial CFD codes. The computational conditions are given in Table 4. In order to reproduce the geometries of the surrounding building blocks, data from an identical CAD file was used. This CAD file was produced from the drawing of the experimental model.

Table 4. Computed cases for building complex in actual urban area (Test Case E)

\begin{tabular}{|c|c|c|c|}
\hline \multirow{2}{*}{ CFD Code } & Code O & Code M & Code T \\
\cline { 2 - 4 } & Self-made code & Commercial code & Commercial code \\
\hline $\begin{array}{c}\text { Computational } \\
\text { method and time } \\
\text { integral scheme }\end{array}$ & $\begin{array}{c}\text { Overlapping structured } \\
\text { grid }\end{array}$ & Structured grid & Unstructured grid \\
\cline { 2 - 4 } Turbulence model & Artificial compressibility & SIMPLE, steady state & SIMPLE, steady state \\
\hline $\begin{array}{c}\text { Scheme for } \\
\text { advection term }\end{array}$ & $3^{\text {rd }}$-order Upwind & Standard k- $\varepsilon$ & Standard k- $\varepsilon$ \\
\hline \multirow{2}{*}{$\begin{array}{c}\text { Grid } \\
\text { arrangements }\end{array}$} & QUICK & MUSCL(2 ${ }^{\text {nd }}$-order) \\
\hline
\end{tabular}

Although CFD simulations have been performed for sixteen different wind directions, only the wind distributions for wind directions of NNE and W, which are the prevailing wind directions in Niigata City, are shown here. Since there were no clear differences observed between the horizontal distributions of scalar velocity near ground surface as predicted by the three CFD codes, only the results with Code T were presented (cf. Fig. 4). This figure illustrates the horizontal distributions of scalar velocity near ground surface $(\mathrm{z}=2 \mathrm{~m})$. The values in Fig. 4 are normalized by the velocity value at the same height at inflow boundary. Fig. 5 shows a comparison of CFD results with wind tunnel experiments. It was found that the scalar velocity predicted by all CFD codes tends to be smaller in the wake region compared to the experimental value. This discrepancy is mainly due to the fact that $\mathrm{k}-\varepsilon$ model cannot reproduce the vortex shedding from tall buildings, similarly as in Test Case A. This problem is absent in LES results but the computational cost for adopting LES is still beyond the scope of practical applications. In order to overcome this drawback, the adaptation of Hybrid RANS/LES and DES (Detached-Eddy Simulation) [90-93] would be needed. The current state of these approaches will be shown in the invited lectures at this conference by Profs. Hanjalic and Squires [94,95]. 


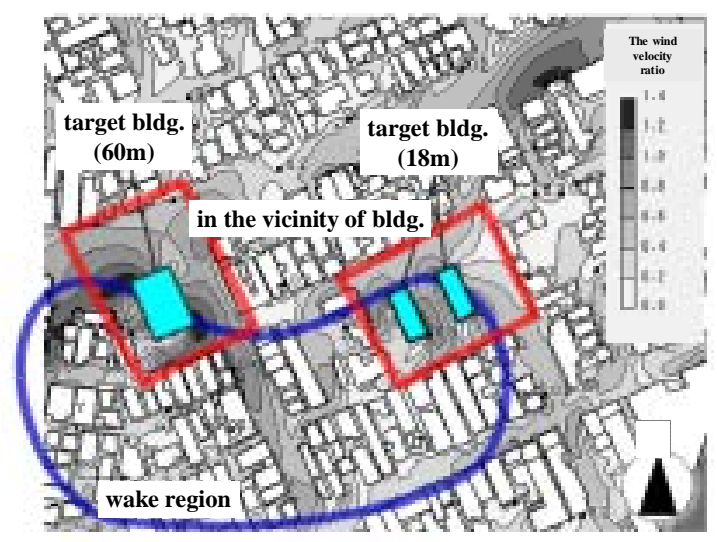

(1) Wind direction: NNE

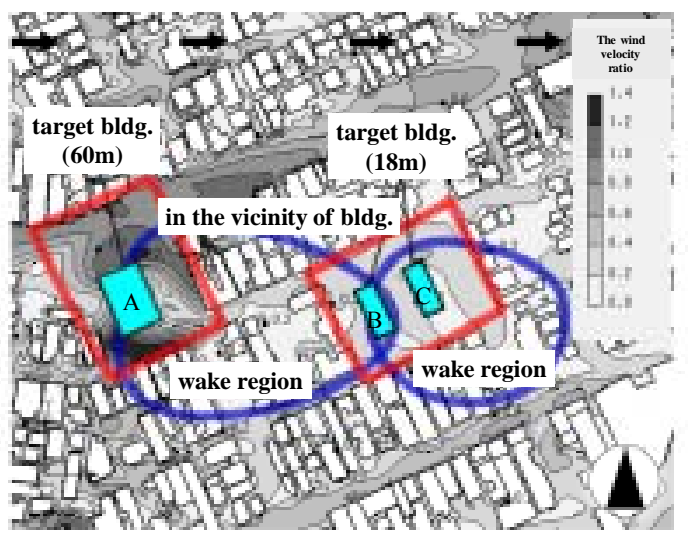

(2) Wind direction: $\mathbf{W}$

Figure 4. Distributions of scalar velocity near ground surface around building complex [79-84]

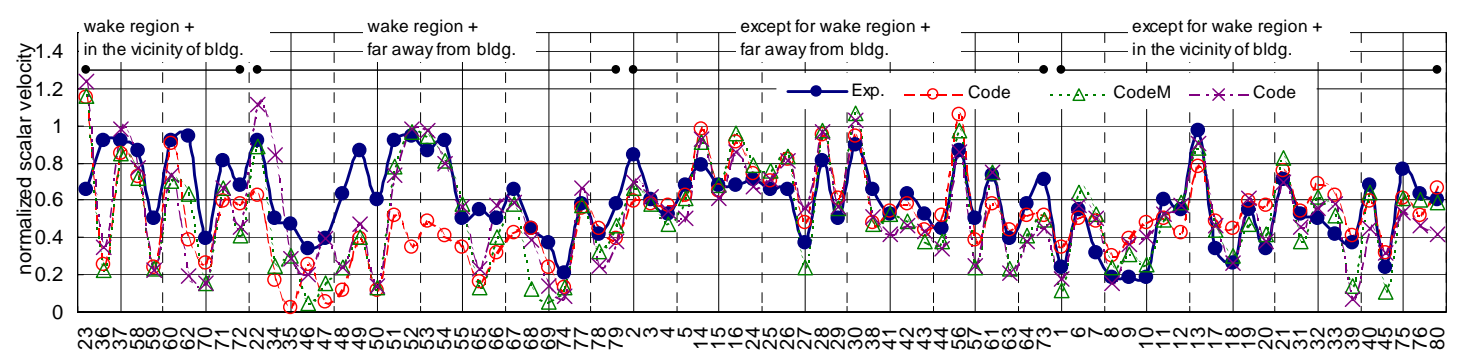

(1) Wind direction: NNE

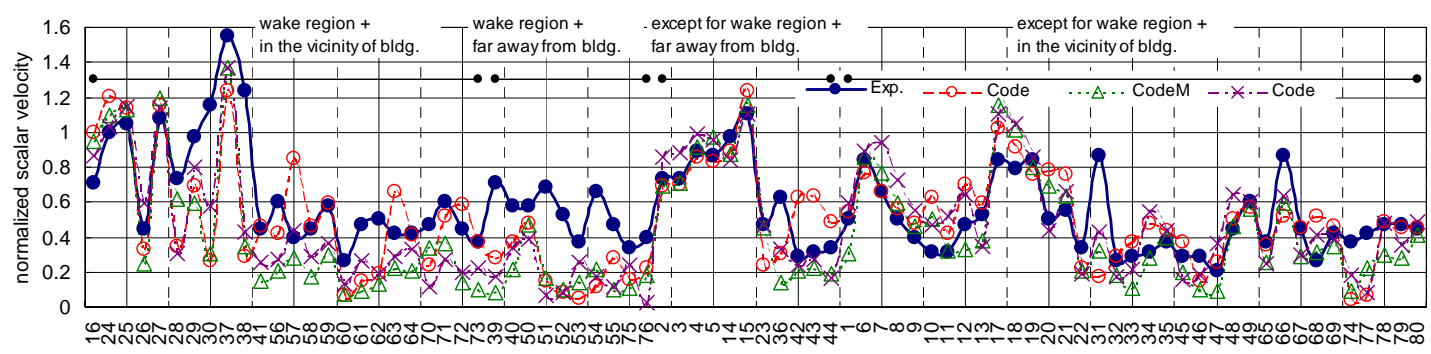

(2) Wind direction: $\mathrm{W}$

Figure 5. Comparison of scalar velocity value for each measurement[79-84]

\section{MODELLING OF SMALL SCALE FLOW OBSTACLES}

\subsection{Various subgrid-scale obstacles in real situations}

The real situations of environment in street canyons are influenced under the interaction of various objects, both stationary and non-stationary. In most of the previous CFD simulations of flow around buildings, only the influences of topographic features and building geometry were considered (cf. Figure 1(1)). At the height of pedestrian level, influences of small obstacles such as trees (stationary) and automobiles (non-stationary) are significant (cf. Figures 1(2) and 1(3)). Their effects have been neglected in most of the studies in the conventional way of CFD prediction of wind environment, but modeling on the effects of such subgrid scale flow obstacles have been investigated in recent years by many researchers. 


\subsection{Modeling for aerodynamic and thermal effects of tree canopy}

\subsubsection{Outline of tree canopy model for reproducing various effects of planted trees}

Tree planting is one of the most popular measures of environmental design for improving outdoor climate. It reduces strong wind around high-rise buildings, improves outdoor thermal comfort, etc. In order to reproduce the effects of trees, a lot of researches have been conducted [96-110]. Prof. Hiraoka is one of the pioneers in this research field. He continuously developed models for expressing aerodynamic effects of trees [97], stomatal conductance [102] radiative heat transfer $[103,104]$, balance of heat, water vapour and carbon dioxide within vegetation canopy $[105,106]$. The present model developed by Hiraoka is very comprehensive and can provide very accurate prediction of microclimate within vegetation canopy, provided that proper input parameters are given. From the viewpoint of engineering application, however, it is usually not easy to apply this model because it requires too many input parameters, some of which are usually not available now. Yoshida et al. [108] developed a 3D tree canopy model which can be easily applied to the practical applications related to micro-scale climate prediction. It includes the following effects (cf. Figure 6):

(1) aerodynamic effects of planted trees

(2) thermal effects

- shading effects on short-wave and long-wave radiations

- productions of water vapour (latent heat) and sensible heat from planted trees

Yoshida et al. predicted the effects of tree planting on outdoor thermal comfort by using coupled simulation of convection (CFD) and radiation combined with the tree canopy model $[108,111]$. Figure 7 illustrates the outline of computational approach for predicting outdoor thermal comfort. Four equations: (1) transport equation of momentum, (2) transport equation of temperature, (3) transport equation of moisture, and (4) heat transfer equation by radiation are solved with coupling manner.

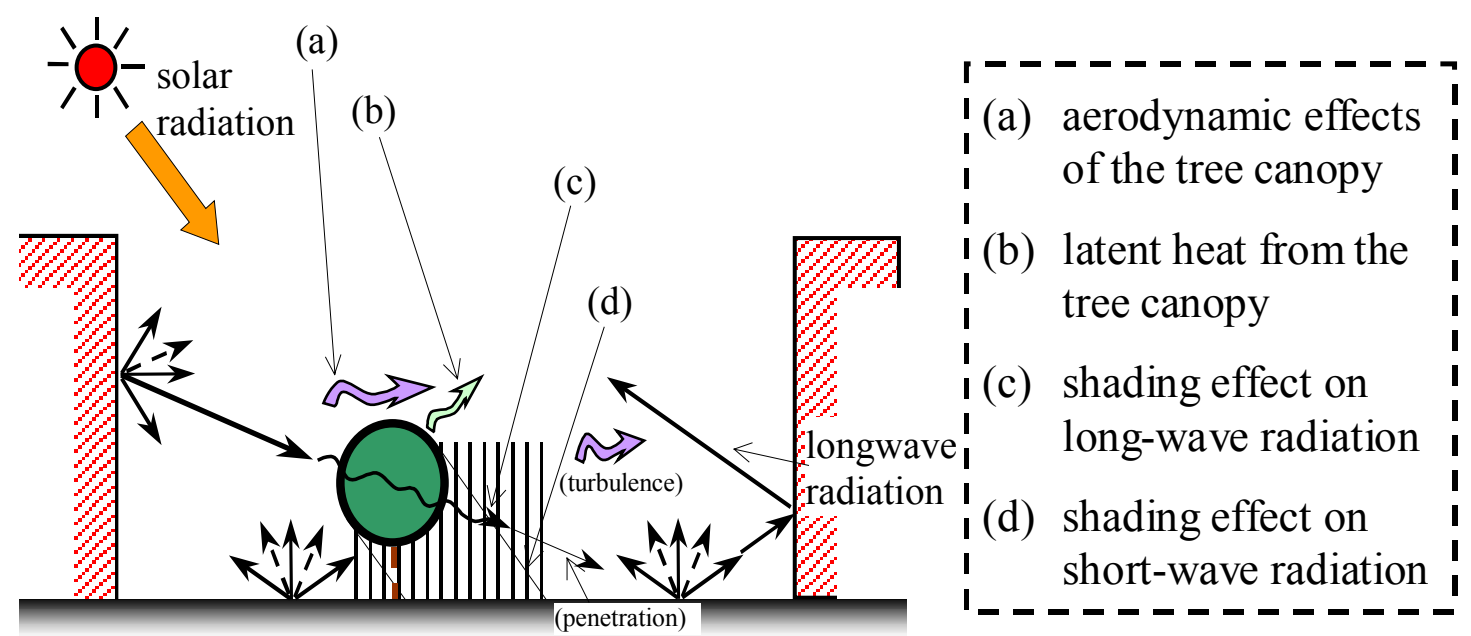

Figure 6. Effects of tree being considered by the tree canopy model [108]. 


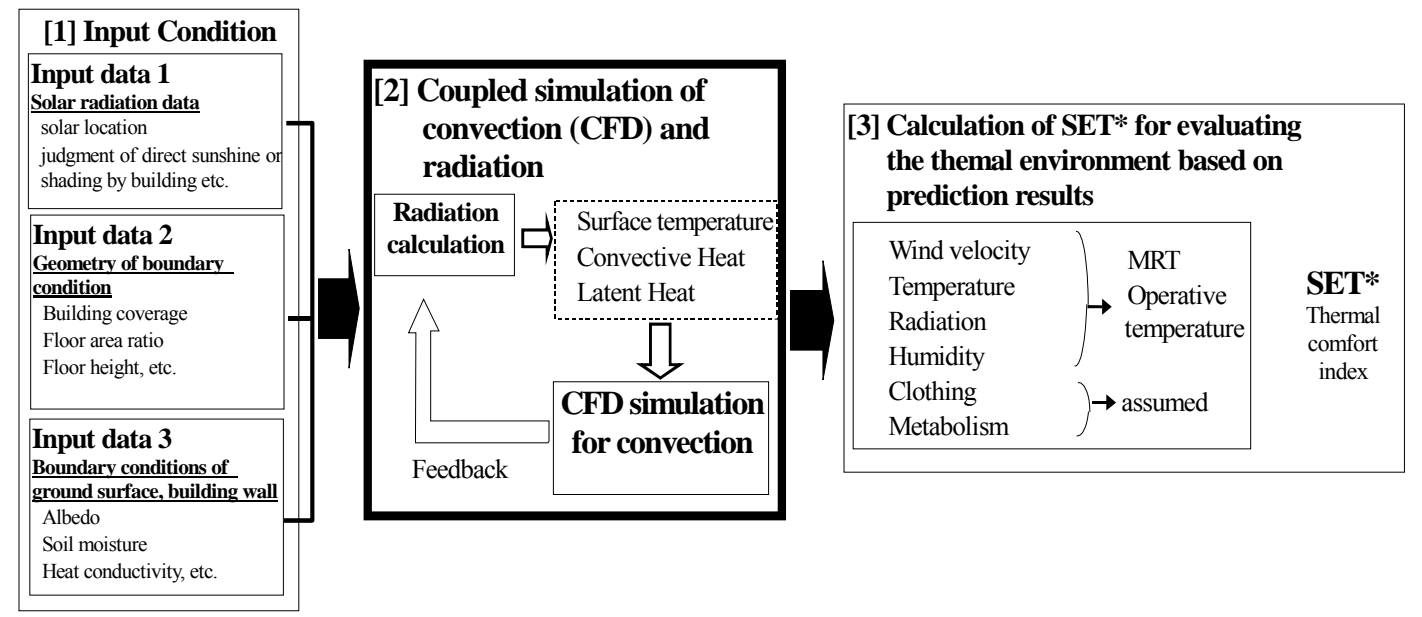

Figure 7. Flowchart for assessing outdoor human comfort based on CFD [78,108,111].

This 3D canopy model employed the k- $\varepsilon$ turbulence model with extra terms (cf. Table 5) added into the transport equations, to simulate the aerodynamic effects of trees. The term $\mathrm{F}_{\mathrm{i}}$ included in the $i$ component of momentum equation denotes the drag force. $\mathrm{F}_{\mathrm{k}}$ and $\mathrm{F}_{\varepsilon}$ added, respectively, into the transport equations of turbulent energy, $\mathrm{k}$, and energy dissipation rate, $\varepsilon$, to represent the effects of trees on turbulent flowfield. These extra terms were derived by applying the spatial average to the basic equation [97]. The radiative heat transport was computed using the method based on Monte-Carlo simulation [112]. The solar and longwave radiant fluxes incident to the plant canopy were calculated by assuming a decay rate of $\left\{1-\exp \left(-k^{\prime} a\left(x_{1}, x_{2}, x_{3}\right) l\right)\right\}$, where $k^{\prime}$ is the absorption coefficient and $l$ is the length by which radiant flux passes through the plant canopy. The mean leaf surface temperature of the plant canopy was estimated using the heat balance equations listed in Table 6 . In the heat balance equation (27), the heat conductivity term is neglected as heat capacity of leaf was negligibly small.

Table 5. Additional terms for tree canopy [108]

\begin{tabular}{|l|l|l|}
\hline $\mathrm{Fi}$ & $-\eta C_{f} a\left(x_{1}, x_{2}, x_{3}\right)<u_{i}>\sqrt{\left.<u_{j}\right\rangle^{2}}$ & (24) \\
\hline $\mathrm{F}_{\mathrm{k}}$ & $\left\langle u_{i}\right\rangle F_{i}$ & (25) \\
\hline $\mathrm{F}_{\varepsilon}$ & $\frac{\varepsilon}{k} C_{p \varepsilon} F_{i}$ & (26) \\
\hline
\end{tabular}

$\eta \quad$ : green coverage ratio,

$C_{f} \quad:$ drag coefficient,

$a\left(\mathrm{x}_{1}, \mathrm{x}_{2}, \mathrm{x}_{3}\right) \quad$ : leaf surface area density,

$<>$ : ensemble-average 
Table 6. Heat balance equations of plant canopy [108]

\begin{tabular}{|l|c|c|}
\hline \multicolumn{2}{|c|}{$S_{P}+R_{D P}+H_{P}+L E_{P}=0$} & $(27)$ \\
\hline$H_{P}=A_{P} \alpha_{C}\left(T_{a P}-T_{P}\right)$ & $(28)$ \\
\hline$L E_{P}=A_{P} \alpha_{W} \beta_{P} L\left(f_{a P}-f_{s P}\right)$ & $(29)$ \\
\hline \\
where,
\end{tabular}

Results with this model were given by Yoshida et al. [108]. Based on the similar approaches, various studies have been conducted in recent years to investigate the effects of planted trees on outdoor thermal environment and optimize their shapes, densities and layouts [113-115].

\subsubsection{Optimization of tree canopy model for reproducing the aerodynamic effects}

Recently, the present authors carried out a series of numerical studies to examine the accuracy of the existing canopy models in reproducing the aerodynamic effects of trees, and to optimize the model coefficients included in them $[73,109,110]$. The canopy models adopted in these studies used the revised k- $\varepsilon$ model, which based on a "mixed time-scale" concept (S- $\Omega$ model), as a base, with extra terms added into the transport equations as shown in Table 5 . The additional terms contained four parameters, $\mathrm{C}_{\mathrm{p} \varepsilon}, \eta, a$ and $\mathrm{C}_{\mathrm{f}} \cdot{ }{ }^{\mathrm{C}} \mathrm{C}_{\mathrm{p} \varepsilon}$ " was regarded as a model coefficient in turbulence modelling for prescribing the time-scale of the process of energy dissipation in the canopy layer, whilst " $\eta$ ", " $a$ " and " $\mathrm{C}_{\mathrm{f}}$ " were the parameters which should be determined according to the conditions of trees. The choice of $\mathrm{C}_{\mathrm{p} \varepsilon}$ value included in $\mathrm{F}_{\varepsilon}$ (cf. eq. (26) in Table 5) affects much on the prediction accuracy [110], and considerable difference was observed between the values adopted in the previous researches [96-108]. The $\mathrm{C}_{\mathrm{p} \varepsilon}$ was optimized by the present authors and predicted results were compared with experimental results. Figure 8 shows an example of such comparison. The value of 1.8 was selected for $\mathrm{C}_{\mathrm{p} \varepsilon}$ as a result of a series of numerical experiments. The tree canopy model developed here was incorporated in the LAWEPS [73,117]. A five-stage nesting grid system was adopted in the LAWEPS. The largest domain ( $1^{\text {st }}$ Domain) covered an approximate region of a scale about $500 \mathrm{~km} \times 500 \mathrm{~km}$ in horizontal directions, and $10 \mathrm{~km}$ in vertical direction. The smallest domain $\left(5^{\text {th }}\right.$ domain) occupied region of about $1 \mathrm{~km} \times 1$ $\mathrm{km} \times 1 \mathrm{~km}$. Figures 9(1) and 9(2) compare the vertical velocity profiles predicted by LAWEPS with the tower observations at Shionomisaki Peninsular, Wakayama, Japan [117]. It can be seen that the results of numerical prediction show very close agreement with the observations. 


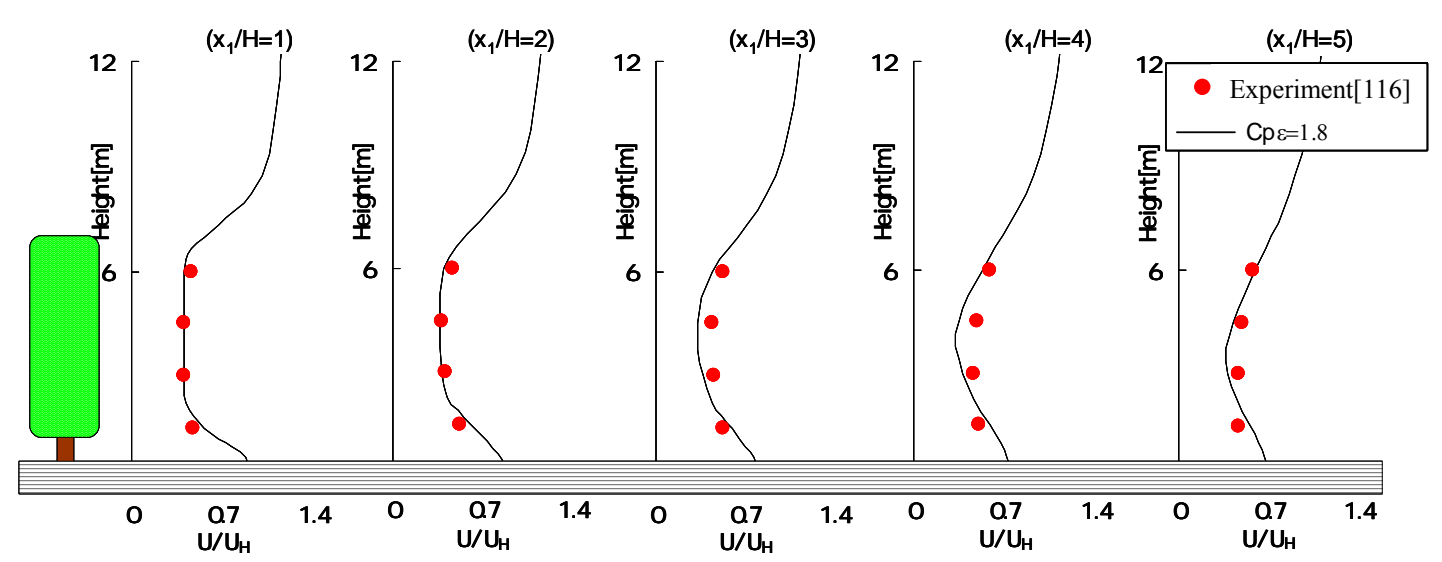

Figure 8. Comparison of normalized vertical profiles of mean streamwise velocity behind pine trees $\left(\mathrm{H}\right.$ : a height of tree, $\mathrm{U}_{\mathrm{H}}$ : inflow velocity at a height of $\left.\mathrm{H}\right)[109,110]$.

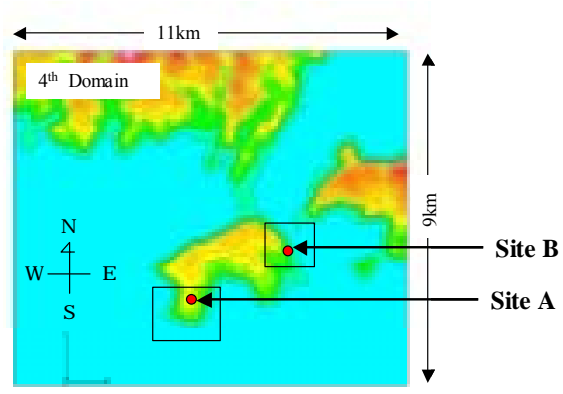

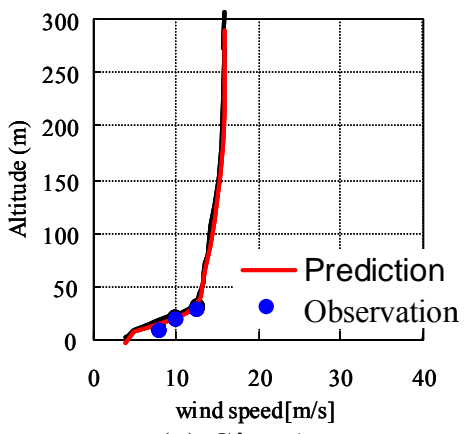

(a) Site A

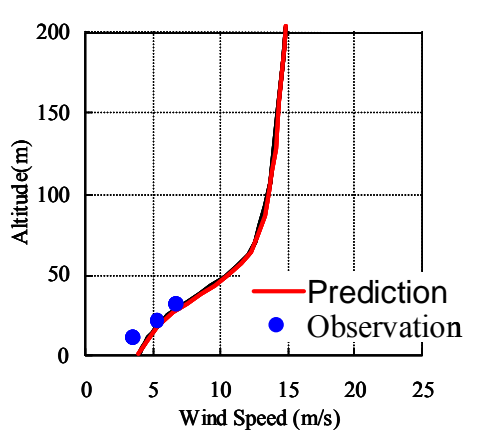

(b) Site B

Figure 9. Comparison of vertical velocity profiles above Shionomisaki Peninsular, Wakayama, Japan (Dec.15th, 15JST, 2001) [117].

The present authors have lately carried out an extensive review on tree canopy models. Four types of canopy models were selected for investigating the aerodynamic effects of trees on wind environment at pedestrian level. The model coefficients adopted in the extra term added to the transport equation of energy dissipation rate, $\varepsilon$, were optimized by comparing the numerical results with field measurements. The four selected tree canopy models [96-101,107] are based on $\mathrm{k}-\varepsilon$ model as given in Table 7 .

Table 7. Additional terms in various tree canopy models

\begin{tabular}{|c|c|c|c|c|}
\hline & $F_{i}$ & $F_{k}$ & $F_{\varepsilon}$ & \\
\hline Type A & \multirow{4}{*}{$\eta C_{f} a\left\langle u_{i}\right\rangle \sqrt{\left\langle u_{j}\right\rangle^{2}}$} & $\left\langle u_{i}\right\rangle F_{i}$ & $\eta \frac{\varepsilon}{k} \cdot C_{p \varepsilon 1} \frac{k^{3 / 2}}{L} \quad\left(L=\frac{1}{a}\right)$ & Hiraoka [97] : $\mathrm{C}_{\mathrm{pel}}=0.8 \sim 1.2$ \\
\hline Type B & & $\left\langle u_{i}\right\rangle F_{i}$ & $\frac{\varepsilon}{k} \cdot C_{p \varepsilon 1} F_{k}$ & $\begin{array}{l}\text { Yamada [96]: } \mathrm{C}_{\mathrm{pl} 1}=1.0 \\
\text { Uno et al. [98] : } \mathrm{C}_{\mathrm{pl} 1}=1.5 \\
\text { Svensson [99]: } \mathrm{C}_{\mathrm{pl} 1}=1.95 \\
\end{array}$ \\
\hline Type C & & $\overline{\left\langle u_{i}\right\rangle} F_{i}-4 \eta C_{f} a \sqrt{\left\langle\overline{\left\langle u_{j}\right\rangle}\right.}$ & $\frac{\varepsilon}{k}\left[C_{p s 1}\left(\left\langle\overline{\left(u_{i}\right\rangle} F_{i}\right)-C_{p s 2}\left(4 \eta C_{f} a \sqrt{\overline{\left\langle u_{j}\right\rangle}}\right)^{2}\right)\right]$ & $\begin{array}{l}\text { Green [100]: } \mathrm{C}_{\mathrm{ps} 1}=\mathrm{C}_{\mathrm{pe} 2}=1.5 \\
\text { Liu et al. [101] : } \mathrm{C}_{\mathrm{ps} 1}=1.5, \mathrm{C}_{\mathrm{pz} 2}=0.6\end{array}$ \\
\hline Type D & & $\overline{\left\langle u_{i}\right\rangle} F_{i}-4 \eta C_{f} a \sqrt{\left\langle\overline{\left\langle u_{j}\right\rangle}\right.}{ }^{2}$ & $\eta \frac{\varepsilon}{k} \cdot C_{p \varepsilon 1} \frac{k^{3 / 2}}{L}$ & Ohashi [107] : $\mathrm{C}_{\mathrm{ps}}=2.5$ \\
\hline
\end{tabular}

The same forms of " $F_{i}$ " were used in all the tree canopy models, and two types of modeling were proposed for $F_{k}$. For Types A and B in Table $5, F_{k}$ was expressed as follows: 
$F_{k}=<u_{i}>F_{i} \quad(<>$ : ensemble-average $)$

In Types $\mathrm{C}$ and $\mathrm{D}, F_{k}$ is modified to include an additional sink term, i.e.

$F_{k}=$ Production $\left(P_{k}\right)$ - Dissipation $\left(D_{k}\right)$

Where, $P_{k}$ : production of $\mathrm{k}$ within canopy $\left(=<\mathrm{u}_{\mathrm{i}}>\mathrm{F}_{\mathrm{i}}\right)$

$D_{k}$ : a sink term to express the turbulence energy loss within canopy [100]

In Types $\mathrm{A}$ and $\mathrm{D}, F_{\varepsilon}$ is modeled by using the length scale " $L$ " within canopy.

$F_{\varepsilon} \propto \frac{1}{\tau}\left(\frac{k^{3 / 2}}{L}\right) \quad($ here $\tau=k / \varepsilon$ and $L=1 / a)$

On the other hand, $F_{\varepsilon}$ is given by the following relation in Type B

$F_{\varepsilon} \propto \frac{1}{\tau} F_{k} \quad$ (here $\tau=k / \varepsilon$ )

In Type $\mathrm{C}$, the term corresponding to the sink term in eq. (31) is added for the expression of $F_{\varepsilon}$.

$$
\begin{gathered}
F_{\varepsilon}=\text { Production }\left(P_{\varepsilon}\right)-\text { Dissipation }\left(D_{\varepsilon}\right) \\
P_{\varepsilon} \propto \frac{1}{\tau} P_{k}, \quad D_{\varepsilon} \propto \frac{1}{\tau} D_{k}
\end{gathered}
$$

As seen in Table 7, the additional terms contain five parameters, two model coefficients, $\mathrm{C}_{\mathrm{p} \varepsilon 1}$ and $\mathrm{C}_{\mathrm{p} \varepsilon 2}, \eta, a$ and $\mathrm{C}_{\mathrm{f}}$. Results with Type $\mathrm{B}$ and Type $\mathrm{C}$ models will be compared with measurements in the presentation at this conference by the present authors [110].

\subsection{Modeling for aerodynamic effects of vehicle canopy [118,119]}

Recently, the present authors developed a simulation method named 'vehicle canopy model' to predict the effects of moving automobiles on flow and diffusion fields whith street canyons $[118,119]$.

\subsubsection{Outline of vehicle canopy model}

In this model, the effects of each individual moving automobile were not directly modeled, instead, the total effects of all the moving automobiles on the street were considered as a whole. The aerodynamic effect of the moving automobiles was modeled based on the methodology of canopy model. The proposed vehicle canopy model was derived based on the $\mathrm{k}-\varepsilon$ model, in which extra terms were added into the transport equations. Similarly to the tree canopy model [96-101,107,110], the extra term "- $F_{i}$ " was added in the momentum equation, cf. Table 8 , which produced the effect of moving automobiles on velocity change. This " $-F$ " was defined as a function of wind velocity $\left\langle\mathrm{u}_{\mathrm{i}}>\right.$ in the tree canopy model (cf. Tables 5 and 7). In modeling vehicle canopy, $<\mathrm{u}_{\mathrm{i}}>$ was replaced by the relative velocity between wind velocity and moving speed of automobiles (cf. Figure 10). In order to simulate the effects of moving automobiles on turbulence increase rate and energy dissipation rate, additional terms " $+F_{k}$ " and " $+F_{\varepsilon}$ " were included in the 
transport equations of turbulent kinetic energy, $\mathrm{k}$, and energy dissipation rate, $\varepsilon$. Table 8 describes the function of these extra terms $[118,119]$.

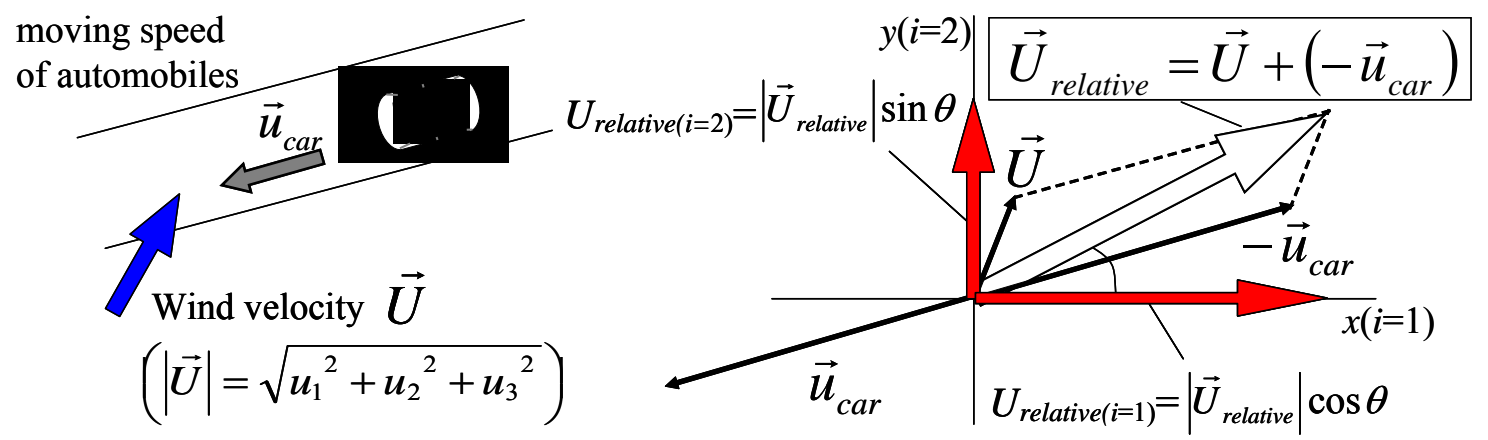

Figure 10. Relationship between wind velocity and moving speed of automobiles.

Table 8 . Additional terms for vehicle canopy model [118,119]

\begin{tabular}{|c|c|c|c|c|}
\hline $\mathrm{F}_{\mathrm{i}}$ & $\frac{1}{2} C_{f-\text { car }} \frac{A_{\text {car }}}{V_{\text {cell }}}\left(<u_{i}>-u_{i-\text { car }}\right) \sqrt{\left(<u_{j}>-u_{j-\text { car }}\right)^{2}}$ & $(35)$ & $\begin{array}{l}\mathrm{C}_{\mathrm{f} \text {-car }} \\
\mathrm{A}_{\text {car }} \\
{\left[\mathrm{m}^{2}\right]} \\
\mathrm{V}_{\text {cell }}\end{array}$ & $\begin{array}{l}\text { : drag coefficient of automobiles } \\
\text { : sectional area of automobiles observed from } i \text { direction } \\
: \text { volume of one computational mesh }\left[\mathrm{m}^{2}\right]\end{array}$ \\
\hline $\mathrm{F}_{\mathrm{k}}$ & $\left(<u_{i}>-u_{i-c a r}\right) F_{i}$ & (36) & $u_{i-c a r}$ & : moving speed of automobiles $[\mathrm{m} / \mathrm{s}]$ \\
\hline $\mathrm{F}_{\varepsilon}$ & $\frac{\varepsilon}{k} \frac{k^{3 / 2}}{L} C_{\varepsilon-c a r}$ & (37) & $\begin{array}{l}\mathrm{L} \\
\mathrm{C}_{\varepsilon \text {-car }}\end{array}$ & $\begin{array}{l}\text { : length scale for canopy layer } \\
\text { : ratio of turbulence scale of automobiles }\end{array}$ \\
\hline
\end{tabular}

\subsubsection{CFD analyses of flowfield in real situations in street canyon}

By using the proposed vehicle canopy model, the flow and diffusion fields within Jozenjistreet in Sendai, Japan, Figure 11, were predicted. The accuracy of CFD analyses was confirmed by comparing the simulation results with the field measurement results conducted by the present authors $[113,120]$. Details of the numerical settings can be obtained from $[118,119]$.

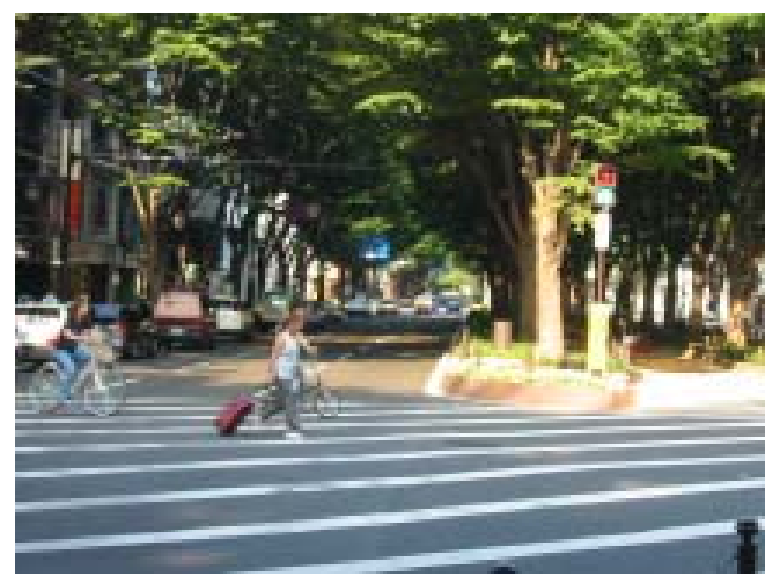

Figure 11. Actual urban space; Jozenji street, Sendai, Japan.

All the test cases are shown in Table 9. Horizontal distributions of wind velocity vectors at a height of $1.5 \mathrm{~m}$ for Case 1 are illustrated in Figure 12. A comparison of the results of turbulent kinetic energy, $\mathrm{k}$, between field measurements and CFD analyses in Jozenji-street is given in Table 10 . In the cases without automobiles (Cases 1 and 2), $k$ values were largely under-predicted 
in comparison with the measurement results. However, the magnitude of $k$ due to turbulent diffusion generated by moving automobiles was well reproduced in Case 3-2, especially on the southern sidewalk.

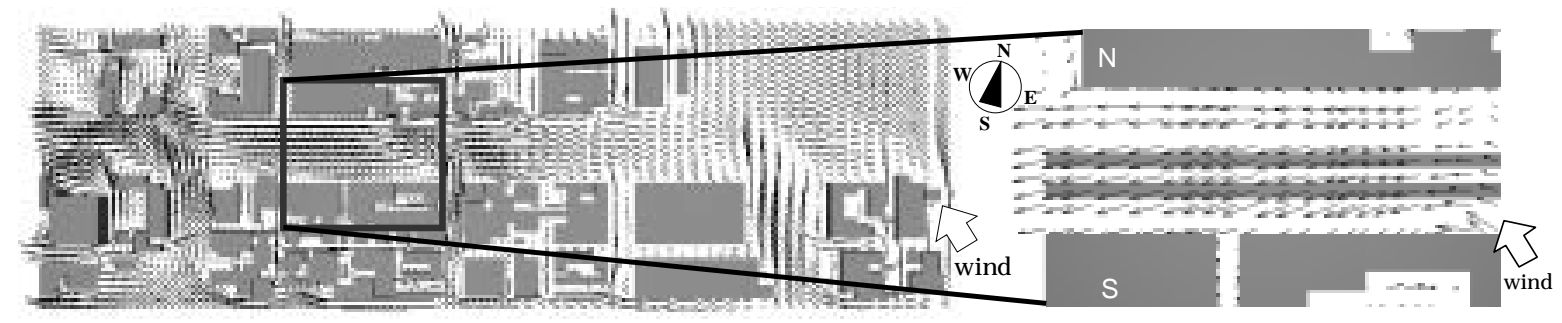

Figure 12. Horizontal distributions of wind velocity vectors

(without trees and automobiles, 12:00a.m. on August $3^{\text {rd }}$ at a height of $1.5 \mathrm{~m}$ ) $[118,119]$.

Table 9. Test cases for vehicle canopy model [118,119]

\begin{tabular}{|l|l|l|}
\hline & Roadside trees & $\begin{array}{l}\text { Effects of moving automobiles } \\
\text { on turbulent diffusion process }\end{array}$ \\
\hline Case 1 & Without & Without automobiles \\
\hline Case 2 & Present situation & Without automobiles \\
\hline Case $3-1$ & Present situation & $u_{c a r}=0[\mathrm{~km} / \mathrm{h}]$ \\
\hline Case $3-2$ & Present situation & $u_{c a r}=15[\mathrm{~km} / \mathrm{h}]$ \\
\hline
\end{tabular}

Table 10. Comparison of turbulent kinetic energy, $k\left[\mathrm{~m}^{2} / \mathrm{s}^{2}\right][118,119]$

\begin{tabular}{|c|c|c|c|c|c|}
\hline \multirow{2}{*}{ Measuring points } & Result of field & \multicolumn{4}{|c|}{ Results of CFD analyses } \\
\cline { 3 - 6 } & measurement & Case 1 & Case 2 & Case 3-1 & Case 3-2 \\
\hline Northern sidewalk & 0.44 & 0.06 & 0.07 & 0.02 & 0.22 \\
\hline Southern sidewalk & 0.27 & 0.12 & 0.03 & 0.03 & 0.25 \\
\hline
\end{tabular}

\subsection{Modeling for aerodynamic and thermal effects of building canopy [123,127]}

Temperature increase due to urbanization is becoming very serious in Japan. City administrators and urban planners are now willing to adopt countermeasures that can mitigate the problem of UHI effects. Various urban planning scenarios have been proposed to minimize the impact of urbanization on urban climate. Since mid-1990s, a lot of numerical studies of mesoscale climate in urban areas have been carried out by many researchers [121-126].

Historically, one-dimensional heat balance model was usually adopted for the ground boundary conditions of mesoscale climate analysis. In this conventional model, a roughness parameter was employed in order to present the effect of the building complex. As the vertical grid size adjacent to the ground surface must be made several times larger than the roughness length in the conventional model, physical phenomena within the surface layer could not be estimated. Furthermore, the definition of surface temperature is vague in the conventional model because its relationship with ground, roof and wall surface temperature is unclear. Therefore, it is necessary to include the effects of urban canopy precisely in order to analyze the thermal environment at pedestrian level in an urban area. On the other hand, the one-dimensional urban canopy model was also commonly used to analyze urban thermal environments. Although this model can predict the thermal environment at pedestrian level easily, it is not possible to consider the effects of local climate due to the limitation of the assumption of a horizontally homogeneous flow and temperature field.

Recently, Ooka et al. [123] developed a comprehensive urban canopy model that considers the following five factors in dealing with building complex: (1) wind reduction by the building 
complex, (2) production of turbulence by the building complex, (3) solar radiation (short-wave) heat transfer inside and outside the building complex, (4) long-wave radiation heat transfer inside and outside the building complex, and (5) sensible and latent heat transfer from the building surfaces. The urban canopy model developed in their study was incorporated into the meteorological mesoscale model [123]. The effects of plant canopy as illustrated in Figure 6 were also considered. Concerning the modeling of aerodynamic effects of the building canopy, i.e. (1) and (2), Prof. Maruyama developed a building canopy model [127], which has been widely used by many researchers. He also provided detailed database obtained by a series of wind tunnel tests to determine the model coefficients included in his model.

\section{INTEGRATION OF CWE SIMULATIONS WITH VARIOUS SCALES}

CWE applications now cover various phenomena in various scales ranging from microclimate around a human body to regional climate (cf. Figure 13). These phenomena of various scales are related and coupled to each other. Research efforts, thus, should be devoted to develop a method for integrating the sub-models into a comprehensive and total simulation system. For this purpose, it is necessary to develop a new software platform which not only can handle many sub-systems for analyzing each scale phenomena but also can integrate them for evaluating the total urban climate. Figure 14 illustrates the concept of the platform proposed by Murakami, Mochida, Ooka et al. [128-130].

A number of case studies based on the proposed Software Platform were presented by Prof. S. Murakami and the present authors $[129,130]$. It was pointed out that CWE is now in the process of growing from a tool for analysis to the tool for environmental design.

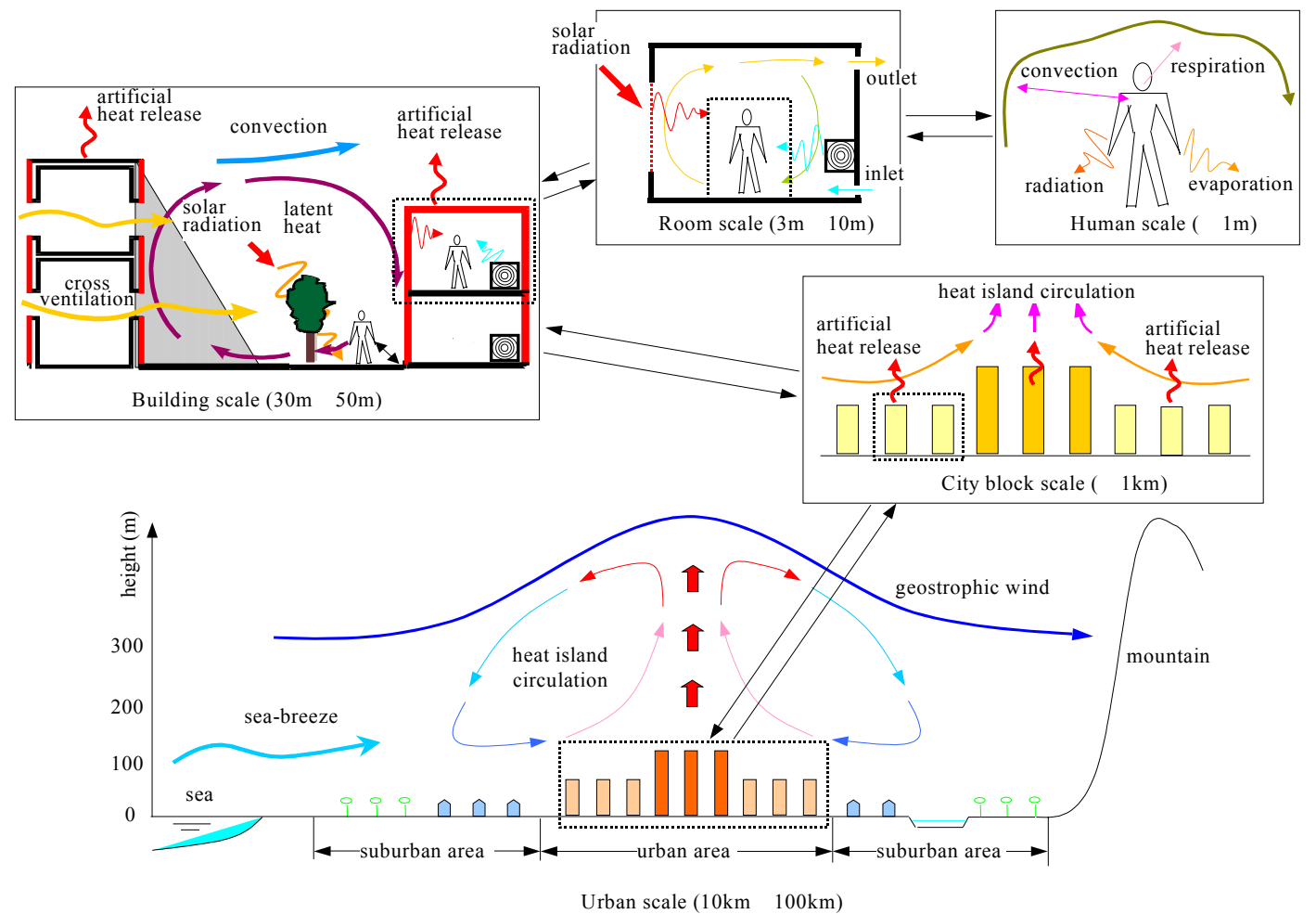

Figure 13. Various scale phenomena related to wind climate $[128,129]$. 


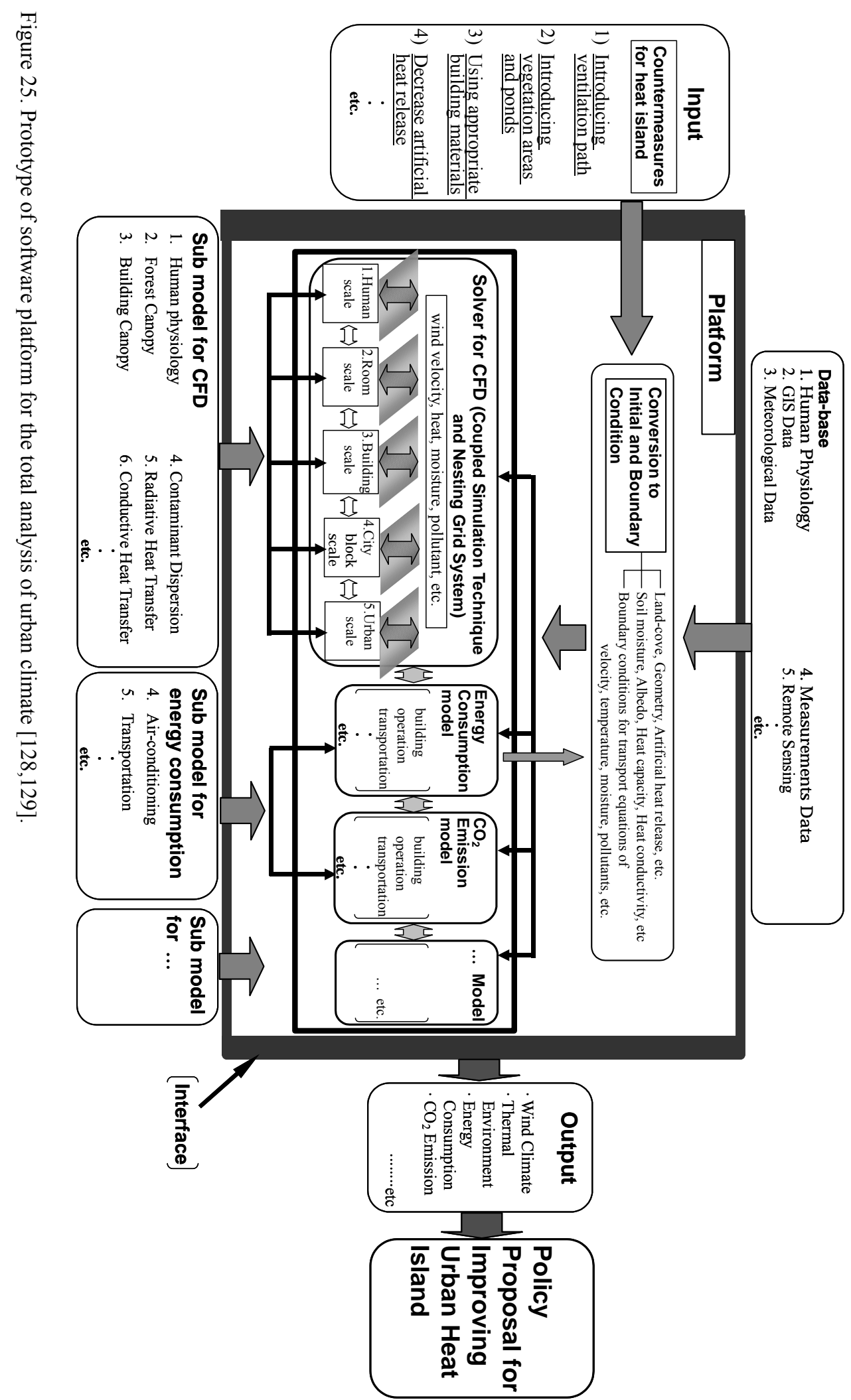




\section{CONCLUDING REMARKS}

This paper reviewed the progress in CWE researches over the past 10 years primarily achieved by the researchers in the field of environmental engineering. The first part of the paper outlined the progress in turbulence modeling for predicting turbulent flow around buildings and wind environment in building complex. In 1990s, many researches were carried out to examine the performance of the dynamic LES models based on the Dynamic Smagorinsky type, Dynamic Mixed type, Lagrangian Dynamic type, etc. Various methods for generating inflow turbulence for LES were developed during the same period. Presently researches to improve the prediction accuracy of k- $\varepsilon$ models are still continued. The performance of various revised k- $\varepsilon$ models was examined for flow around a bluff body, city building blocks, actual building complex and flow over hilly terrains. It was confirmed that the revised $k-\varepsilon$ models which were proposed to correct the drawback of the standard k- $\varepsilon$ model that severely over-predicts the turbulence energy, $\mathrm{k}$, around front corners could undoubtedly improve the prediction accuracy for predicting the strong wind in separated flow regions around front corners. However, all revised k- $\varepsilon$ models over-predicted the sizes of reattachment lengths behind buildings and under-predicted the velocity values in the wake regions. This discrepancy is mainly due to the fact that all k- $\varepsilon$ models could not reproduce the vortex shedding from buildings. This problem was not observed in LES results but computational cost for LES is still beyond the scope of practical applications. In order to overcome this drawback, the adaptation of Hybrid RANS/LES and DES (Detached-Eddy Simulation) would be needed.

The latter part of the paper described the recent and future trends of numerical modeling for predicting the wind and thermal environment as well as turbulent diffusion process in real urban space where there exist various small subgrid scale flow obstacles. The conventional approach in numerical modeling is generally carried out based on static condition (i.e. stationary objects such as buildings). This method may be erroneous when applying to real situation where dynamic condition exists (i.e. non-stationary objects such as automobiles). In recent years, canopy models for reproducing the aerodynamic and thermal effects of trees/buildings/automobiles have been developed and applied to various problems related to urban climate. This paper demonstrated some of the results regarding this subject. The research studies emphasised on the significance of the effects of stationary and non-stationary objects (tree canopy model and vehicle canopy model respectively) on turbulent flowfield within street canyons.

As indicated in Section 4 in this paper, the development of the total simulation system integrating the sub-model for the phenomena with various scales makes it possible to carry out total analysis of urban climate which composes of many elements and controls by many interacting physical processes at various scales. CWE is now in the process of growing from a tool for analysis to a tool for environmental design. However, a lot of improvements and revisions are still required before the turbulent flow phenomena in urban areas can be accurately reproduced. Hence, fundamental research efforts to improve the prediction accuracy should be continued.

\section{Acknowledgements}

This paper reviewed the recent progress in CWE applied on environmental problems. Many topics included in this report are the results of collaborations extended over years with Prof. S. Murakami (Keio University), Prof. Y. Tominaga (Niigata Institute of Technology), Prof. R. Ooka (IIS, University of Tokyo), Dr. S. Iizuka (National Institute of Resources and Environment), Prof. S. Yoshida (Fukui University), Dr. K. Kondo (Kajima Corporation), Dr. K. Sasaki (Shimizu corporation) and Dr. T. Shirasawa (Tokyo Inst. Polytechnics). The authors are grateful for 
their valuable contributions. The assistance in preparing this manuscript by Mr. K.Takahashi (Tohoku University) is gratefully acknowledged.

[Note 1]: The works involved in this project are divided into three phases. During the initial phase of the study, a multi-step wind simulation with nesting method was designed. In the second phase of the work, each sub-model was coded and evaluated. Data of observations and experiments were obtained in parallel and used for verification with computation. In the final phase of the project, the performance of the entire simulation system, LAWEPS, was tested and examined by comparing its results with measured data [73,117].

[Note 2]: The CFD Working Group members are: A. Mochida (Chairman, Tohoku Univ.), Y. Tominaga (Secretary, Niigata Inst. of Tech.), Y. Ishida (I.I.S., Univ. of Tokyo), T. Ishihara (Univ. of Tokyo), K. Uehara (National Inst. of Environ. Studies), R. Ooka (I.I.S., Univ. of Tokyo), H. Kataoka (Obayashi Corp.), T. Kurabuchi (Tokyo Univ. of Sci.), N. Kobayashi (Tokyo Inst. Polytechnics), T. Shirasawa (Tokyo Inst. Polytechnics), N. Tuchiya (Takenaka Corp.), Y. Nonomura (Fujita Corp.), T. Nozu (Shimizu Corp.), K. Harimoto (Taisei Corp.), K. Hibi (Shimizu Corp.), S. Murakami (Keio Univ.), T. Yamanaka (Kajima Corp.), R. Yoshie (Tokyo Inst. Polytechnics), M. Yoshikawa (Taisei Corp.).

\section{REFERENCES}

1 World Urbanization Prospects: The 2001 Revision, Dept of Economic and Social Affairs Population Division, UN, (//www.un.org/esa/population/publications/wup2001/WUP2001_CH1.pdf).

2 Cooling our communities: A guidebook to tree planting and light colored surfacing, A. Akabari, S. Davis, S. Dorsano, J. Huang and S. Winnett (Eds.), U.S. EPA, Washington, DC, (1992).

3 E.G. McPherson and R.A. Rowntree, Energy conservation potential of urban tree planting, J. Arboric., 19(6) (1993), 321-331.

4 R.A. Rowntree, Ecological values of the urban forest, In Proc. $4^{\text {th }}$ Urban Forestry Conference, American Forestry Association, Washington, DC, (1989), 22-25.

5 M. Germano, U. Piomelli, P. Moin and W.H. Cabot, A Dynamic subgrid scale eddy viscosity model, Phys. Fluids, A3(7) (1991), 1760-1765.

6 D.K. Lilly, A proposed modification of the Germano subgrid-scale closure method, Phys. Fluids, A4(3) (1992), 633-635.

7 J.H. Ferziger, Large eddy simulation, In T.B. Gatski, M. Y. Hussain and J.L. Lumley (Eds.), Simulation and Modeling of Turbulent Flows, Oxford University Press, USA, (1996).

8 A. Mochida, S. Murakami, Y. Tominaga and H. Kobayashi, Large eddy simulation of turbulent vortex shedding flow past 2D square cylinder using Dynamic SGS model (Part1), J. Archit. Plann. Environ. Eng., AIJ No. 479 (1996), 41-47. (in Japanese)

9 W. Rodi, J.H. Ferziger, M. Breuer and M. Pourquie, Status of large eddy simulation: results of workshop, Transaction of the ASME. J. Fluids Engg., 119 (1997), 248-262.

10 P.R. Voke, Flow past a square cylinder: test case LES2, In J.P. Chollet, P.R. Voke and L. Kleiser (Eds.), Direct and Large-eddy Simulation II, $2^{\text {nd }}$ ERCORTAC Workshop, Gronouble, France, 1996 Springer, (1997).

11 S. Murakami, S. Iizuka, A. Mochida and Y. Tominaga, LES analysis of turbulent flow past a square cylinder using various SGS models. In J.P. Chollet, P.R. Voke and L. Kleiser (Eds.), Direct and Large-eddy Simulation II, $2^{\text {nd }}$ ERCORTAC Workshop, Gronouble, France, 1996, Springer, (1997), 385-395.

12 S. Murakami, A. Mochida and S. Iizuka, New trends in turbulence models for prediction of wind effects on structures, IWEF Workshop on CWE/CFD for prediction of Wind Effects on Structures, (1996), 1-52

13 S. Murakami and A. Mochida, Past, present, and future of CWE: the view from 1999, In A. Larsen, G.L. Larose and F.M. Livesey (Eds.), Wind Engineering into the $21^{\text {st }}$ Century, Proc. $10^{\text {th }}$ Int. Conf. on Wind Engineering, Copenhagen, Denmark, A.A. Balkema, Rotterdam, (1999), 91-104.

14 C. Meneveau, T. S. Lund and W. H. Cabot, A Lagrangian dynamic subgrid-scale model of turbulence, J. Fluid Mech., 319 (1996), 353-385.

15 S. Murakami, R. Ooka and S. Iizuka, CFD analysis of flow past two-dimensional square cylinder using dynamic LES, J. Fluid and Structures, 13 (1999), 1097-1112.

16 S. Iizuka, S. Murakami, A. Mochida, Y. Tominaga, H. Kobayashi and K. D. Squires, Large eddy simulation of turbulent vortex shedding flow past 2D square cylinder using Dynamic SGS model (Part3), Archit. Plann. Environ. Eng., AIJ No. 511 (1998), 39-43. (in Japanese) 
17 Y. Zang, R.L. Street and J.R. Koseff, A dynamic mixed subgrid scale model and its application to turbulent recirculating flows, Phys. Fluids, A5(12) (1993).

18 B. Vreman, B. Geurts and H. Kuerten, On the formulation of the dynamic mixed subgrid-scale model, Phys. Fluids, A6 4057 (1994).

19 J. Bardina, J.H. Ferziger and W.C. Reynolds, Improved subgrid-scale models for Large-Eddy Simulation, AIAA paper-80 (1981).

20 Y. Tominaga, A. Mochida, S. Murakami and S. Iizuka, Large eddy simulation of turbulent vortex shedding flow past 2D square cylinder using Dynamic SGS model (Part2), J. Archit. Plann. Environ. Eng., AIJ No. 492 (1997), 57-62. (in Japanese)

21 Y. Tominaga, A. Mochida and S. Murakami, LES prediction of gas diffusion near building using dynamic mixed SGS model based on composite grid technique, J. Archit. Plann. Environ. Eng., AIJ No. 496 (1997), 5358. (in Japanese)

22 Y. Tominaga, S. Murakami \& A. Mochida, CFD prediction of gaseous diffusion around a cubic model using a dynamic mixed SGS model based on composite grid technique, J. Wind Eng. Ind. Aerodyn., 67 \& 68 (1997), 827-841.

23 S. Iizuka and H. Kondo, Large eddy simulation of turbulent flow over complex terrain (Part1), J. Environ. Eng., AIJ No. 568 (2003), 41-48. (in Japanese)

24 S. Iizuka, R. Ooka, S. Murakami, A. Mochida and S. Kato, LES Analysis of Channel Flow using Dynamic SGS model, Proceedings of $30^{\text {th }}$ Symposium on Turbulence, (1998), 193-194. (in Japanese)

25 M. Inagaki, T. Kondoh and Y. Nagano, A Mixed-Time-Scale SGS Model for practical LES, Transaction of the Japan society of mechanical engineers, B Vol. 68, No. 673 (2002), 2572-2579. (in Japanese)

26 K. Abe, T. Kondoh and Y. Nagano, A New Turbulence Model for Predicting Fluid Flow and Heat Transfer in Separating and Reattaching Flows - II. Thermal Field Calculations, Int. J. Heat Mass Transfer, Vol.38, No.8 (1995), 1467-1481.

27 S. Iizuka and H. Kondo, Large eddy simulation of turbulent flow over complex terrain (Part2), J. Environ. Eng., AIJ No. 576 (2004), 23-28. (in Japanese)

28 A. Mochida, S. Murakami, M. Shoji and Y. Ishida, Numerical simulation of flowfield around Texas Tech building by large eddy simulation, J. Wind Eng. Ind. Aerodyn., 46 \& 47 (1993) 455-460.

29 S. Lee, S.K. Lele and P. Moin, Simulation of spatially evolving turbulence and the applicability of Taylor's hypothesis in compressible flow, Phys. Fluids, A4(7) (1992), 1521-1530.

30 K. Kondo, S. Murakami and A. Mochida, Generation of velocity fluctuations for inflow boundary condition of LES, J. Wind Eng. Ind. Aerodyn., 67 \& 68 (1997), 51-64.

31 K. Kondo, A. Mochida and S. Murakami, Generation of inflow turbulence for LES, J. Struct. Constr. Eng., AIJ No. 501 (1997), 33-40. (in Japanese)

32 K. Kondo, A. Mochida and S. Murakami, Generation of inflow turbulence for turbulent boundary layer, J. Struct. Constr. Eng., AIJ No. 509 (1998), 33-40. (in Japanese)

33 S. Iizuka, S. Murakami, N. Tsuchiya and A. Mochida, LES of flow past 2D cylinder with imposed inflow turbulence, Proc. $10^{\text {th }}$ Int. Conf. on Wind Eng., Copenhagen, Denmark, Vol. 2 (1999), 1291-1298.

34 S. Iizuka, A. Mochida, S. Murakami, S. Lee and K. Kondo, Generation of inflow Turbulence for LES based on 3D Energy Spectrum in Wave Number Space, Proc. of $14^{\text {th }}$ National symposium on wind engineering, (1996), 223-226. (in Japanese)

35 T. Maruyama, W. Rodi, Y. Maruyama and H. Hiraoka, LES simulation of the turbulent boundary layer behind roughness elements using an artificially generated inflow, The $4^{\text {th }}$ Asia-Pacific Symposium on Wind Engineering, Volume of Abstract, (1997), 371-374.

36 T.S. Lund, X. Wu. and K. D. Squires, Generation of turbulent inflow data for spatially-developing boundary layer simulations, J. Comp. Phys., 140 (1998), 233-2588.

37 H. Kataoka and M. Mizuno, Numerical flow computation around aeroelastic 3D square cylinder using inflow turbulence, Wind and Structures, 5(2-4) (2002), 379-392.

38 Y. Tominaga, A. Mochida, S. Murakami and S. Sawaki, Large Eddy Simulation of flowfield around A Highrise Building (Part 1),J. Environ. Eng., AIJ, No.581, (2004), 45-51. (in Japanese)

39 T. Shirasawa, A. Mochida, Y. Tominaga and H. Yoshino, Examination of the revised k- $\varepsilon$ models based on mixed time-scale concept using LES data, Summaries of Technical Papers of Annual Meeting, Environ. Engg. II, AIJ (2004), 841-842. (in Japanese)

40 Y. Ishida, A. Mochida, Y. Tominaga and T. Shirasawa, LES of Flow around a High-rise Building with Generated Inflow Turbulence, Proc. $17^{\text {th }}$ Symposium on Numerical Fluid Dynamics, E6-1 (2003). (in Japanese)

41 W. Rodi, A New Algebraic Relation for Calculating the Reynolds Stresses ZAMM 56, 1976, T219-T221.

42 S. Murakami, A. Mochida, Y. Kondo and T. Tanaka, Numerical simulation of air flow around surfacemounted square rib by means of algebraic stress model, J. Archit. Plann. Environ. Eng., AIJ No. 419 (1991) 19. (in Japanese) 
43 B.E. Launder, G.J. Reece and W. Rodi, Progress in the development of a Reynolds-stress turbulence closure, J. Fluid Mech., 68 (1975), 537-566.

44 S. Murakami, A. Mochida and Y. Hayashi, Scrutinizing k- $\varepsilon$ EVM and ASM by means of LES and wind tunnel for flowfield around cube, Prep. of $8^{\text {th }}$ Symp. on Turbulent Shear Flows, Munich, Germany, (1991), 17-1-1 17-1-6.

45 S. Murakami, A. Mochida and R. Ooka, Numerical simulation of flowfield over surface-mounted cube with various second-moment closure models, Prep. of $9^{\text {th }}$ Symp. on Turbulent Shear Flows, Kyoto, Japan, (1993), 13-5-1 13-5-6.

46 R. Ooka, A. Mochida, S. Murakami and Y. Hayashi, Examining ASM by means of wind tunnel test, LES and DSM numerical simulation of anisotropic turbulent flowfield, J. Archit. Plann. Environ. Eng., AIJ No. 495 (1997), 61-68. (in Japanese)

47 R. Ooka, S. Murakami and A. Mochida, Study on modeling for $\Phi_{\mathrm{ij}}, \Phi^{\mathrm{w}}{ }_{\mathrm{ij}}$ and turbulent diffusion of $\left\langle\mathrm{u}_{\mathrm{i}}{ }^{\prime} \mathrm{u}_{\mathrm{j}}{ }^{\prime}>\right.$, J. Archit. Plann. Environ. Eng., AIJ No. 504 (1998), 55-61. (in Japanese)

48 S. Fu, B.E. Launder and D.P. Tselepidakis, Accommodating the effects of high strain rates in modeling the pressure-strain correlation, UMIST Mech. Eng. Dept. Rep., (1987), TFD/87/5.

49 C.G. Speziale, S. Sarkar and T.B. Gatski, Modeling the pressure-strain correlation of turbulence: an invariant dynamical system approach J. Fluid Mech., 227 (1991), 245-272.

50 M.M. Gibson and B.E. Launder, Ground effects on pressure fluctuations in the atmospheric boundary layer, J. Fluid Mech., (1978), 491-511.

51 T.J. Craft and B.E. Launder, A new model of 'Wall-Reflection' effects on the pressure-strain correlation and its application to the turbulent impinging jet, AIAA J., 30 (1992), 2970.

52 J.C. Rotta, Statistsche thorie nichthomogner turbulenz. Zeitscr Physcs., 129 (1951), 547-572. (in German)

53 C.C. Shir, A preliminary numerical study of atmospheric turbulent flow in the idealized planetary boundary layer. J. Atmos. Sci., 30 (1973), 1327-1339.

54 K. Hanjalic and S. Obi (Eds.), Proc. of $6^{\text {th }}$ ERCOFTAC/IAHR/COST Workshop on Refined Flow Modeling, Delft University of Technology, (1997).

55 S. Murakami, A. Mochida and Y. Hayashi, Examining the k- $\varepsilon$ model by means of a wind tunnel test and largeeddy simulation of the turbulence structure around a cube, J. Wind Eng. Ind. Aerodyn., 35 (1990), 87-100.

56 A. Mochida, S. Murakami and Y. Hayashi, Comparison between k-e model and LES for turbulence structure around cube, J. Archit. Plann. Environ. Eng., AIJ No.423 (1991), 23-31. (in Japanese)

57 B.E. Launder and M. Kato, Modeling flow-induced oscillations in turbulent flow around a square cylinder, ASME Fluid Eng. Conf., (1993).

58 M. Kato and B.E. Launder, The modeling of turbulent flow around stationary and vibrating square cylinders, Prep. of $9^{\text {th }}$ Symp. on Turbulent Shear Flow, (1993), 10-4-1 10-4-6. (in Japanese)

59 C.G. Speziale, On nonlinear k-1 and k- $\varepsilon$ models of turbulence, J. Fluid Mech., 178 (1987), 459-475.

60 T.H. Shih, J. Zhu and J.L. Lumley, A realizable Reynolds stress algebraic equation model, NASA, (1993), TM-105993.

61 T.J. Craft, B.E. Launder and K. Suga, A non-liner eddy viscosity model including sensitivity to stress anisotropy, Proc. $10^{\text {th }}$ Symp. on Turbulent Shear Flows, Penn State Univ., (1995), 23/19-23/24.

62 K. Kondo, S. Murakami and A. Mochida, Numerical simulation of flowfield around 2D square rib using revised k- $\varepsilon$ model, Proc. $13^{\text {th }}$ Japan National Symp. on Wind Eng., (1995), 515-520. (in Japanese)

63 D. Lakehal and W. Rodi, Calculation of the flow past a surface-mounted cube with two-layer turbulence models, J. Wind Eng. Ind. Aerodyn., 67 \& 68 (1997), 65-78.

64 W. Rodi, Comparison of LES and RANS calculations of the flow around bluff bodies, J. Wind. Eng. Ind. Aerodyn., 69-71 (1997), 55-75 (BBAA III, Blacksburg, VA, USA, 1996).

65 M. Tsuchiya, S. Murakami, A. Mochida, K. Kondo and Y. Ishida, Development of new k- $\varepsilon$ model for flow and pressure fields around bluff body, J. Wind. Eng. Ind. Aerodyn., 67 \& 68 (1997), 169-182.

66 P.A. Durbin, On the k-e stagnation point anomaly., Int. J. Heat and Fluid Flow, 17 (1996), 89-90.

67 A. Mochida, Y. Tominaga, S. Murakami, R. Yoshie, T. Ishihara and R. Ooka, Comparison of various k- $\varepsilon$ models and DSM applied to flow around a high-rise building-report on AIJ cooperative project for CFD prediction of wind environment, Wind and Structures, 5/2-4 (2002), 227-244.

68 Working group for CFD prediction of wind environment around building, Air Environment Sub-committee, Environment engineering committee, AIJ 2001, Development of CFD method for predicting wind environment around a high-rise building, J. Technol. Des., AIJ No. 12 (2001), 119-124. (in Japanese)

69 Y. Tominaga, A. Mochida, S. Murakami and S. Sawaki, Comparison of performance of various revised k- $\varepsilon$ models applied to CFD analysis of flowfield around high-rise building, J. Archit. Plann. Environ. Eng., AIJ No. 556 (2002), 47-54. (in Japanese) 
70 F. Nakayama, T. Kurabuchi, M. Ohba, T. Endo and Y. Fugo, A study on Evaluation of Cross-Ventilation performance of opening part6, Summaries of Technical Papers of Annual Meeting, Environ. Engg. II, (2002), 723-724. (in Japanese)

71 Y.F. Lun, A. Mochida, S. Murakami, H. Yoshino and T. Shirasawa, Numerical Simulation of Flow over Topographic Features by Revised k-e Model, J. Wind Eng. Ind. Aerodyn., 91 (2003), 231-245.

72 Y. Nagano and H. Hattori, A new low-Reynolds number turbulence model with hybrid time-scale of mean flow and turbulence for complex wall flow, In K. Hanjalic, Y. Nagano and F. Arinc (Eds.), Proc. $4^{\text {th }}$ Int. Symp. on Turbulence, Heat and Mass Transfer, Antalya, Turkey, (2003).

73 S. Murakami, A. Mochida and S. Kato, Development of local area wind prediction system for selecting suitable site for windmill, J. Wind Eng. Ind. Aerodyn., 91 (2003), 1759-1776.

74 A. Mochida, T. Shirasawa, H. Yoshino, S. Murakami and Y. Tominaga, 2003. CFD Analysis of Flow around a Cube using Revised k- $\varepsilon$ Model Based on Mixed Time Scale Concept, Conference Preprints of $11^{\text {th }}$ International Conference on Wind Engineering, Vol. 1 (2003), 1149-1156.

75 T. Shirasawa, A. Mochida, H. Yoshino, S. Murakami and Y. Tominaga, CFD analysis of flowfield around building using revised k- $\varepsilon$ models, Proc. of $17^{\text {th }}$ National symposium on wind engineering, (2002), 201-206. (in Japanese)

76 Y. Meng and K. Hibi, An experimental study of turbulent boundary layer over steep hills, Proc. $15^{\text {th }}$ National Symp. on Wind Engineering, (1998), 61-66. (in Japanese)

77 B.E. Launder, On the computation of convective heat transfer in complex turbulent flows Trans. ASME, J. Heat Transfer, 110 (1988), 112-128.

78 S. Yoshida, S. Murakami, R. Ooka, A. Mochida and Y. Tominaga; Influence of green area ratio on outdoor of convection, radiation and moisture transport, Computational Wind Engineering 2000 (2000), 27-30.

79 Y. Tominaga, A. Mochida, T. Shirasawa, R. Yoshie, H. Kataoka, K. Harimoto and T. Nozu, Cross comparisons of CFD results of wind environment at Pedestrian level around a high-rise building and within a building complex, J. Asian Architecture and Building Engineering, Vol. 3, No. 1 (2004), 63-70.

80 R. Yoshie, A. Mochida, Y. Tominaga, H. Kataoka, K. Harimoto, T. Nozu and T. Shirasawa, Cooperative Project for CFD Prediction of Pedestrian Wind Environment in the Architectural Institute of Japan, CD Pro Proceedings of EACWE4-The fourth European \& African Conference on Wind Engineering (2005), Paper \#292.

81 R. Yoshie, A. Mochida, Y. Tominaga, H. Kataoka and M. Yoshikawa, Cross Comparison of CFD Prediction for Wind Environment at Pedestrian Level around Buildings ( Part 1), Proceedings of The Sixth Asia-Pacific Conference on Wind Engineering (APCWE-VI), (2005), 2648-2660.

82 Y. Tominaga, R.Yoshie, A. MochidaH. Kataoka, K. Harimoto and T. Nozu, Cross Comparison of CFD Prediction for Wind Environment at Pedestrian Level around Buildings ( Part 2), Proceedings of The Sixth AsiaPacific Conference on Wind Engineering (APCWE-VI), (2005), 2661-2670.

83 R. Yoshie, A. Mochida and Y. Tominaga, CFD Prediction of Wind Environment around a High-rise Building Located in an Urban Area, Computational Wind Engineering 2006, (2006).

84 A. Mochida, Y. Tominaga and R. Yoshie, AIJ Guideline for Practical Applications of CFD to Wind Environment around Buildings, Computational Wind Engineering 2006, (2006).

85 H. Kataoka and M. Mizuno, Numerical Flow Computation around Aeroelastic 3D Square Cylinder using Inflow Turbulence, Wind and Structures, , Vol.5, No.2-4 (2002), 379-392.

86 V. Yakhot and S.A. Orsag, Renormalization Group Analysis of Turbulence, J. Sci. Comput. 1, 3 (1986).

87 Y. Tominaga, A. Mochida and S. Murakami, Large Eddy Simulation of Flowfield around A High-rise Building, Conference Preprints of $11^{\text {th }}$ International Conference on Wind Engineering, 2003, Vol. 2, pp. 2543-2550.

88 Y. Tominaga and A. Mochida, CFD Prediction of Flowfield and Snowdrift around Building Complex in Snowy Region, Journal of Wind Engineering and Industrial Aerodynamics, 81, (1999), 272-282.

89 T. Ishihara and K. Hibi, Turbulent Measurements of The Flow Field around A High-rise Building, Journal of Wind Engineering, 76, (1998), 55-64.( in Japanese )

90 P. R. Spalart, Strategies for Turbulence Modelling and Simulations, Engineering Turbulence Modelling and Experiments-4, Elsevier Science Ltd., (1999), 3-17.

91 K. D. Squires, Perspective and Challenges in Simulation and Modeling of Unsteady Flows, CD Proceedings of $17^{\text {th }}$ Japan National Conference on Computational Fluid Dynamics, (2003).

92 F. R. Menter and M. Kunts, Development and Applications of A Zonal DES Turbulence Model for CFX-5, ANSYS CFX Validation Report ( CFX-VAL 17/0703 )

93 S. Kenjers and K. Hanjalic, Dynamical Simulations Towards Optimal Indoor Climate and Safety Control, CD Proceedings of $3^{\text {rd }}$ Dubrovnik Conference on Sustainable Development of Energy, Water and Environment System, Dubrovnik, Croatia, June 2005, (2005).

94 K. Hanjalic, Some Developments in RANS and Hybrid RANS/LES for Wind-and Environment Engineering, Computational Wind Engineering 2006, (2006). 
95 K. D. Squires, Prediction of Turbulent Flows at High Reynolds Numbers using Detached-Eddy Simulation, Computational Wind Engineering 2006, (2006).

96 T. Yamada, A Numerical Model Study of Turbulent Airflow in and Above a Forest Canopy, Journal of the Meteorological Society of Japan, 60/1 (1982), 439-454.

97 H. Hiraoka, Modelling of Turbulent Flows within Plant/Urban Canopies, J. Wind Eng. Ind. Aerodyn., 46 \& 47 (1993), 173-182.

98 I. Uno et al., Numerical modeling of the nocturnal urban boundary layer, Boundary-Layer Meteorol., 49 (1989), 77-98.

99 Svensson et al., A Two-Equation Turbulence Model For Canopy Flows, J. Wind Eng. and Ind. Aerodyn., 35 (1990), 201-211.

100 S.R. Green, Modelling Turbulent Air Flow in a Stand of Widely-Spaced Trees, PHOENICS Journal Computational Fluid Dynamics and its Applications, 5 (1992), 294-312.

101 Liu, J. et al., E- $\varepsilon$ Modelling of Turbulent Air Flow Downwind of a Model Forest Edge, Boundary-Layer Meteorol, 77 (1996), 21-44.

102 H. Hiraoka, I. Uno and H. Nakajima, Nonlinear multi-regression model of stomatal conductance using neural network, J. Archit. Plann. Environ. Eng., AIJ No. 484 (1996), 25-32. (in Japanese)

103 H. Hiraoka, Studies on diffusion approximation method for Ross'es radiation transfer equation within plant canopy, J. Archit. Plann. Environ. Eng., AIJ No. 495 (1997), 31-36. (in Japanese)

104 H. Hiraoka, Examination of diffusion approximation method for Ross'es radiation transfer equation within plant canopy, J. Archit. Plann. Environ. Eng., AIJ No. 512 (1998), 9-15. (in Japanese)

105 H. Hiraoka, Modeling the budgets of heat, water vapor, and carbon dioxide within a tree, J. Archit. Plann. Environ. Eng., AIJ No. 546 (2001), 53-60. (in Japanese)

106 H. Hiraoka, Modeling the budgets of heat and water vapor within vegetation: a verification study, J. Archit. Plann. Environ. Eng., AIJ No. 558 (2002), 31-36. (in Japanese)

107 M. Ohashi, A study on analysis of airflow around an individual tree, J. Environ. Eng., AIJ No. 578 (2004), 91 96. (in Japanese)

108 S. Yoshida, R. Ooka, A. Mochida, S. Murakami and Y. Tominaga, Development of Three Dimensional Plant Canopy Model for Numerical Simulation of Outdoor Thermal Environment, The 6th International Conference on Urban Climate (ICUC 6), Goteborg, Sweden, June 12-16, (2006).

109 A. Mochida, A. Kimura, H. Yoshino, S. Murakami and T. Iwata, NATO Advanced Study Institute - Flow and Transport Processes in Complex Obstructed Geometries from cities and vegetative canopies to industrial problems -, Kyiv, Ukraine, (2004).

110 A. Mochida, H. Yoshino, T. Iwata and Y. Tabata, Optimization of Tree Canopy Model for CFD Prediction of Wind Environment at Pedestrian Level, Computational Wind Engineering 2006, (2006).

111 H. Chen, R. Ooka, K. Harayama, S. Kato and X. Li, Study on outdoor thermal environment of apartment block in Shenzhen, China with coupled simulation of convection, radiation and conduction, Energy and Buildings, 36 (2004), 1247-1258.

112 T. Omori, H. Taniguchi and K. Kudo, Monte_Carlo simulation of indoor radiant environment, Int. J. Numerical Methods in Engineering, 30(4) (1990), 615-627.

113 A. Mochida, T. Iwata, N. Hataya, H. Yoshino, K. Sasaki and H. Watanabe, Field Measurements and CFD Analyses of Thermal Environment and Pollutant Diffusion in Street Canyon, Proceedings of The Sixth AsiaPacific Conference on Wind Engineering (APCWE-VI), (2005), 2681-2696.

114 R. Ooka, H. Chen and S. Kato, Study on Optimum Arrangement of Trees for Design of Pleasant Outdoor Environment Using Multi-Objective Genetic Algorithm, Computational Wind Engineering 2006, (2006).

115 B. Lin, Y. Zhu, X. Li and Y. Qin, Numerical Simulation Studies of The Different Vegetation Patterns' Effects on Outdoor Pedestrian Comfort, Computational Wind Engineering 2006, (2006).

116 Y. Kurotani, N. Kiyotani and S. Kobayashi, Windbreak effect of Tsuijimatsu in Izumo Part.2, Summaries of Technical Papers of Annual Meeting, Environ. Engg. II, (2001), 745-746. (in Japanese)

117 S. Murakami, K. Otsuka, A. Mochida, H. Kataoka and S. Kato, CFD prediction of flow over complex terrain using Local Area Wind Energy Prediction System (LAWEPS), Conference Preprints of $11^{\text {th }}$ International Conference on Wind Engineering, Texas, Vol.2 (2003), 2821-2828.

118 A. Mochida, N. Hataya, T. Iwata, Y. Tabata, H. Yoshino and H. Watanabe, CFD analyses on outdoor thermal environment and air pollutant diffusion in street canyons under the influences of moving automobiles, The 6th International Conference on Urban Climate (ICUC6), Goteborg, Sweden, June 12-16, (2006).

119 Naoko Hataya, Akashi Mochida, Tatsuaki Iwata, Yuichi Tabata, Hiroshi Yoshino and Y. Tominaga, Development of the simulation method for thermal environment and pollutant diffusion in street canyons with subgrid scale obstacles, Computational Wind Engineering 2006, (2006).

120 H. Watanabe, A. Mochida, K. Sakaida, H. Yoshino, Y. Jyu-nimura, T. Iwata, N. Hataya and K. Shibata. , Field Measurement of Thermal Environment and Pollutant Diffusion in Street Canyon to Investigate the Effects of 
its Form and Roadside Trees, International Symposium on Sustainable Development of Asia City Environment (SDACE 2005), Department of Architecture, Xi'an, China, Nov. 23-25 (2005), 509-515.

121 A. Mochida, S. Murakami, T. Ojima, S. Kim R. Ooka and H. Sugiyama, CFD analysis of mesoscale climate in the Greater Tokyo area, J. Wind Eng. Ind. Aerodyn., 67 \& 68 (1997), 459-477.

122 S. Murakami, A. Mochida, R. Ooka, S. Yoshida, H. Yoshino, K. Sasaki and K. Harayama, Evaluation of the Impacts of Urban Tree Planting in Tokyo Based on Urban Heat Balance Model, Conference Preprints of $11^{\text {th }}$ International Conference on Wind Engineering, , Vol. 2 (2003), 2641-2648.

123 R. Ooka, K. Harayama, S. Murakami and H. Kondo, $5^{\text {th }}$ Symposium on the Urban Environment, Annual Meeting of American Meteorological Society, Vancouver, British Columbia, Canada, (2004), 9-15.

124 H. Kondo, T. Tokairin and Y. Kikegawa, The Wind Calculation in Tokyo Urban Area with A Mesoscale Model, Computational Wind Engineering 2006, (2006).

125 T. Sato, S. Murakami, R. Ooka and S. Yoshida, Analysis of Regional Characteristics of The Atmospheric Heat Balance in The Tokyo Metropolitan Area in Summer, Computational Wind Engineering 2006, CWE2006.

126 K. Sasaki, A. Mochida, T. Yoshida, H. Yoshino and H. Watanabe, A New Method to Select Appropriate Countermeasures against Heat-island Effects according to The Regional Characteristics of Heat Balance Mechanism, Computational Wind Engineering 2006, (2006).

127 T. Maruyama, Optimization of Roughness Parameters for Staggered Arrayed Cubic Blocks using Experimental Data, Journal of Wind Engineering and Industrial Aerodynamics., 46 \& 47 (1993), 165-171.

128 S. Murakami, A. Mochida, S. Kim, R. Ooka, S. Yoshida, H. Kondo, Y. Genchi and A. Shimada, Software platform for the total analysis of wind climate and urban heat island, $3^{\text {rd }}$ International Symposium on Computational Wind Engineering, (2000), 23-26.

129 S. Murakami, Indoor/outdoor Climate Design by CFD based on The Software Platform, International Journal of Heat and Fluid Flow, 25, (2004), 849-863.

130 A. Mochida, Management and Design of Outdoor Environment based on Software Platform for The Total Analysis of Urban Heat Island, CD Proceedings of $3^{\text {rd }}$ Dubrovnik Conference on Sustainable Development of Energy, Water and Environment System, Dubrovnik, Croatia, June 2005, (2005). 